\title{
Possibilidades e desafios da prática de aprendizagem colaborativa no ensino superior
}

\author{
Edna Lampert Klein* \\ Pontifícia Universidade Católica do Paraná \\ Dilmeire Sant'Anna Ramos Vosgerau** \\ Pontifícia Universidade Católica do Paraná
}

Resumen A prática da aprendizagem colaborativa no ensino superior tem por finalidade a construção do conhecimento de forma compartilhada entre os estudantes. Nela, a aprendizagem é um processo partilhado entre os estudantes e mediado pelo docente, que também fomenta a interação, colaboração e desenvolvimento do grupo. Este estudo objetiva descrever os benefícios e os desafios sobre a utilização de práticas de aprendizagem colaborativa no ensino superior, com base em artigos publicados na SciELO. Nesta revisão sistemática, foram localizados 147 artigos que abordam a temática, mas apenas 46 atendiam aos critérios de inclusão: publicação entre 2000 e 2016; pesquisa empírica; e ensino superior. As pesquisas mapeadas definem aprendizagem colaborativa como um trabalho conjunto, interativo e compartilhado, que permite a construção do conhecimento colaborativamente. A totalidade dos artigos que tratam dessa abordagem apresenta a prática como benéfica ao estudante sob diferentes aspectos, tais como: desenvolvimento da autonomia, aprendizagem pelo processo de interação e desenvolvimento da responsabilidade sobre sua própria aprendizagem. Um dos desafios identificados é desvinculá-la do manuseio de tecnologias, visto que a aprendizagem colaborativa independe do seu uso e, consequentemente, é necessário formação docente. Conclui-se que a prática de aprendizagem colaborativa possibilita a construção da aprendizagem e do conhecimento de forma compartilhada entre os estudantes, permanecendo como grandes desafios a compreensão do conceito pelos docentes e aceitação por parte dos estudantes para que possa ser aplicada em contexto de aprendizagem presencial e híbrida no ensino superior, não necessariamente associada ao uso de tecnologia.

PALABRAS CLAVE: Ensino superior; Aprendizagem colaborativa; Revisão sistemática. 


\section{Possibilities and challenges of collaborative learning in Higher Education}

Abstract Practicing collaborative learning in higher education aims to build knowledge in a shared environment among students. In this practice, learning is a process shared by and between students and mediated by the teacher. During this process, the teacher also fosters group interaction, collaboration and development. This study aims to describe the benefits and challenges of using collaborative learning practices in higher education, based on articles published in SciELO. In this systematic review, we found 147 articles that address the practice of collaborative learning, however only 46 met the following criteria: publication between 2000 and 2016, empirical research, and higher education. The mapped research defines collaborative learning as a collective, interactive and shared work that enables the construction of knowledge collaboratively. All the articles dealing with this approach present this practice as beneficial to the student under different aspects, including: developing autonomy, learning through interaction, and developing responsibility for their own learning. One of the challenges we identified is to dissociate the practice of collaborative learning from the use of technologies, since collaborative learning does not depend on them, and, consequently, training the teachers for this dissociation. We concluded that this practice enables the construction of learning and knowledge in a shared way among students. Nevertheless, teacher's understanding of the concept of collaborative learning and its acceptance by students remain great challenges for collaborative learning to be applicable in both face-to-face and hybrid learning, not necessarily associated with the use of technology.

KEYWORDS: Higher education; Collaborative learning; Systematic review.

\section{Introdução}

A educação superior vivencia várias transformações, principalmente quando se discutem as práticas e metodologias de aprendizagem e sua aplicação no contexto do ensino superior, sendo o uso de práticas inovadoras indicado como um suporte para essas mudanças (ADAMS BECKER et al., 2017), por transformar e permitir novas formas de ensinar e aprender. Contudo, isso requer um entendimento sobre sua aplicabilidade, bem como sobre quais estratégias suportam-nas, objetivando resultados significativos.

A aprendizagem colaborativa está entre as práticas que estimulam a autonomia e a construção da aprendizagem e promovem a interação entre os estudantes, sendo também considerada uma estratégia efetiva de ensino e eficaz para a aprendizagem (BARKLEY; MAJOS; CROSS, 2014).

As discussões em torno dessa prática iniciaram-se na América do Norte, entre os anos 1980 e 1990, a partir dos estudos sobre aprendizagem cooperativa reali- 
zados por Johnson, Johnson e Holubec (1988) e Jonhson e Jonhson (1994) no contexto da educação básica. Paralelamente, outros estudos (LEW et al., 1986) sobre o tema abordaram a perspectiva da interdependência dos objetivos de aprendizagem com os resultados e o desenvolvimento de habilidades colaborativas, originando discussões sobre a distinção entre aprendizagem colaborativa e aprendizagem cooperativa (BRUFFEE, 1995), uma vez que o trabalho cooperativo deveria preparar e desenvolver nos estudantes da educação básica habilidades colaborativas necessárias para esse tipo de trabalho no ensino superior, tais como: comunicação, autenticidade, compromisso, tolerância, senso de equipe e confiança.

No fim da década de 1990, diversos autores (BRUFFEE, 1995; PANITZ, 1995; ROCKWOOD, 1995) já distinguiam aprendizagem colaborativa de cooperativa, sendo a colaboração vista como uma filosofia de interação e um estilo pessoal, no qual os estudantes são responsáveis por suas ações. Entre essas ações, estão a responsabilidade sobre sua própria aprendizagem e o respeito e habilidades para trabalhar com seus pares. Logo, a cooperação é uma estrutura criada para a realização de uma atividade ou produção de um produto que requer que os estudantes trabalhem em grupo (PANITZ, 1995).

Quanto ao papel do docente, na aprendizagem cooperativa, as atividades são mais estruturadas e as tarefas, claramente definidas, normalmente trabalhando conhecimentos fundamentais, sendo o docente o centro da autoridade. Já na aprendizagem colaborativa, as atividades são mais complexas, o grupo organiza-se livremente para sua realização, os conhecimentos - trabalhos são de alta complexidade e o docente abdica de sua autoridade, empoderando os grupos (ROCKWOOD, 1995). Essas definições permanecem no estudo de Barkley, Majos e Cross (2014), que declaram que a aprendizagem colaborativa assume um papel muito importante na universidade, devido às possibilidades geradas por sua aplicação, uma aprendizagem mais ativa, proporcionando ação mútua e permitindo o compartilhamento de informação.

Nesse contexto, o estudante toma para si a responsabilidade por construir sua própria aprendizagem, adquirir novas habilidades, realizar discussões em grupo e colaborar ativamente no meio acadêmico. De fato, essa forma de ensinar e aprender torna os alunos mais responsáveis por sua aprendizagem, levando-os a assimilar conceitos e construir conhecimentos de maneira mais autônoma (TORRES; IRALA, 2014).

A aprendizagem colaborativa contribui na formação do estudante por meio de quatro princípios fundamentais: o trabalho conjunto, a interatividade, a aprendizagem compartilhada e a construção de conhecimento coletivo, esperando-se dele o envolvimento ativo na sua própria aprendizagem e a inserção em um contexto social solidário e desafiador (BARKLEY; MAJOS; CROSS, 2014). Dessa forma, possibilita práticas de ensino e aprendizagem compartilhadas, um ambiente em que é possível interagir, discutir, refletir e construir, além da construção conjunta do conhecimento, pelo cumprimento de atividades e objetivos comuns. Com essa prática, os estudantes conseguem desenvolver a intelectualidade e, principalmente, tornam-se mais sociáveis, atingindo e superando metas pessoais, resultado da interação em grupo (BARKLEY; 
MAJOS; CROSS, 2014). Além disso, obtêm resultados positivos e muito mais expressivos quando se envolvem efetivamente no processo colaborativo.

Utilizar essa prática de ensino é estimulante, mas exige que o docente tenha um planejamento adequado e atividades com objetivos claros que desafiem e motivem o grupo. Nesse sentido, ele deve desempenhar o papel de moldar e direcionar os trabalhos, estruturar as tarefas de aprendizagem, monitorar o progresso do grupo e interferir quando os estudantes desviarem-se do objetivo (BARKLEY; MAJOS; CROSS, 2014). Contudo, sua efetivação no ensino superior não depende apenas do docente, mas também de outros fatores, a exemplo da universidade, no que se refere à formação docente, e de políticas que incentivem as boas práticas de ensino.

De acordo com a Organização das Nações Unidas para a Educação, a Ciência e a Cultura (UNESCO, 2012), existe a necessidade de estimular a aplicação de novas práticas de ensino na universidade que incorporem o processo de conhecimento no estudante. Seu uso inovador deve ser orientado para criar relações sociais entre os discentes e apresentar perspectivas na busca da aprendizagem; assim, tais mudanças precisam ser acompanhadas de práticas inovadoras e tecnológicas que motivem os estudantes em seu processo educacional, uma vez que, quando as novas gerações chegam à universidade e vivenciam um cotidiano permeado por novos aparatos e formas de comunicação, conseguem estabelecer dinâmicas inéditas de construção do conhecimento (UNESCO, 2012).

Essas mudanças no ensino superior com a aplicação de novas práticas possibilitam uma aprendizagem mais dinâmica e poderiam atender à demanda apontada no estudo da Unesco, realizado em 2008 e denominado Pesquisa Novos Talentos, no qual se identifica que 92,2\% dos jovens dessa geração aprendem facilmente por meio de tecnologia; $88,2 \%$, com foco na prática; $83,9 \%$, por meio da experiência; e $66,4 \%$, de forma colaborativa (UNESCO, 2012).

Partindo desse princípio com relação ao uso de novas práticas e tecnologias, este estudo busca identificar os desafios da aprendizagem colaborativa no ensino superior, com o objetivo de contribuir para seu fortalecimento na universidade. Para tanto, analisa a produção científica nacional, por meio de pesquisa na Scientific Electronic Library Online (SciELO), até o ano de 2016.

\section{Encaminhamento metodológico}

Para realização desta revisão sistemática, foram associados os pressupostos de procedimentos da Campbell Collaboration (2016), os indicadores de qualidade e etapas de uma revisão sistemática propostos por Thomas e Pring (2007) e as etapas definidas por Schiavon (2015), as quais compreendem: formulação de uma pergunta, busca sistemática, avaliação crítica e estrutura analítica, conforme o Quadro 1. 
Possibilidades e desafios da prática de aprendizagem colaborativa no ensino superior

Quadro 1 - Etapas da revisão sistemática

\begin{tabular}{|l|l|}
\hline Etapas da revisão sistemática & Descrição \\
\hline Formulação de uma pergunta & $\begin{array}{l}\text { Quais os desafios para a prática colaborativa } \\
\text { no ensino superior? }\end{array}$ \\
\hline Busca sistemática & Palavras-chave: \\
& - Aprendizagem colaborativa. \\
& - Base SciELO. \\
& - Filtro de busca: anterior ao ano de 2017 \\
\hline Avaliação crítica & Critérios de inclusão: \\
& - Ensino superior. \\
& - Ano de publicação até 2016. \\
& - Metodologia de pesquisa. \\
& - Relato das conclusões. \\
\hline Estrutura analítica & - Tipo de pesquisa. \\
& - Qualidade da apresentação. \\
& - Relato dos dados. \\
& - Descobertas e conclusões. \\
& - População envolvida. \\
& - Práticas de ensino. \\
\hline
\end{tabular}

Fonte: elaborado pelas autoras (2017).

Considerando as bases de dados geral e nacional, foram recuperados 147 artigos, dos quais 58 estavam duplicados, tendo sido excluídos; por fim, restaram 46 incluídos pelo processo de revisão sistemática, conforme apresentado na Tabela 1.

Tabela 1 - Artigos recuperados

\begin{tabular}{l|l|l|l|l}
\hline Base de dados & $\begin{array}{l}\text { Total } \\
\text { encontrado }\end{array}$ & Duplicados & Total excluído & Total incluído \\
\hline $\begin{array}{l}\text { SciELO } \\
\text { nacional }\end{array}$ & 60 & - & 27 & 33 \\
\hline SciELO geral & 87 & 58 & 74 & 13 \\
\hline Total & 147 & 58 & 101 & 46 \\
\hline
\end{tabular}

Fonte: elaborado pelas autoras (2017).

\section{Conceito de aprendizagem colaborativa}

Após o processo de análise dos artigos publicados na SciELO, identificouse que 20 apresentam uma definição da prática de aprendizagem colaborativa (Quadro 2). Utilizando como categorias de análise os princípios elencados por Barkley, Majos e Cross (2014): trabalho conjunto (TC), interatividade (I), aprendizagem compartilha$\mathrm{da}(\mathrm{AC})$ e construção de conhecimento coletivo (CC), observou-se a presença de pelo menos um deles nos conceitos utilizados nas publicações selecionadas. 
Quadro 2 - Conceito de aprendizagem colaborativa

\begin{tabular}{|c|c|c|c|c|c|}
\hline \multirow{2}{*}{ Referência } & \multirow{2}{*}{ Conceito } & \multicolumn{4}{|c|}{ Categorias } \\
\hline & & TC & I & $\mathrm{AC}$ & $\mathrm{CC}$ \\
\hline $\begin{array}{l}\text { Abegg, Bastos e Müller } \\
(2010)\end{array}$ & $\begin{array}{l}\text { Trabalho em conjunto: } \\
\text { objetivos em comum. }\end{array}$ & $\mathrm{x}$ & & & \\
\hline Aravena-Reyes (2001) & $\begin{array}{l}\text { Interatividade: interação } \\
\text { virtual; conhecimento: } \\
\text { construção coletiva. }\end{array}$ & & $\mathrm{x}$ & & $\mathrm{x}$ \\
\hline Bedran e Salomão (2013) & Trabalho conjunto: divisão. & $\mathrm{x}$ & & & \\
\hline Cogo et al. (2010) & $\begin{array}{l}\text { Trabalho conjunto: divisão e } \\
\text { troca de opiniões. }\end{array}$ & $\mathrm{x}$ & & & \\
\hline $\begin{array}{l}\text { Echavarria e Hernández } \\
\text { (2013) }\end{array}$ & $\begin{array}{l}\text { Trabalho conjunto: } \\
\text { formação e solidificação, } \\
\text { inteligência coletiva; } \\
\text { interatividade: interação } \\
\text { virtual; aprendizagem: } \\
\text { aprendizagem mediada; } \\
\text { conhecimento: construção } \\
\text { coletiva. }\end{array}$ & $\mathrm{x}$ & $\mathrm{x}$ & $\mathrm{x}$ & $\mathrm{x}$ \\
\hline Figueroa e Aillon (2015) & $\begin{array}{l}\text { Trabalho conjunto: } \\
\text { objetivos em comum; } \\
\text { aprendizagem: troca de } \\
\text { aprendizagem. }\end{array}$ & $\mathrm{x}$ & & $\mathrm{x}$ & \\
\hline Giannotti e Diniz (2010) & $\begin{array}{l}\text { Interatividade: } \\
\text { interação virtual; } \\
\text { aprendizagem: ensino e } \\
\text { troca de aprendizagem; } \\
\text { conhecimento: experiências } \\
\text { adquiridas. }\end{array}$ & & $\mathrm{x}$ & $\mathrm{x}$ & $\mathrm{x}$ \\
\hline González-Weil et al. (2014) & $\begin{array}{l}\text { Trabalho conjunto: } \\
\text { objetivos em comum. }\end{array}$ & $\mathrm{x}$ & & & \\
\hline Marchiori e Greef (2014) & $\begin{array}{l}\text { Trabalho conjunto: ações } \\
\text { conjuntas, objetivos } \\
\text { em comum, liderança } \\
\text { compartilhada, confiança } \\
\text { mútua, condução das } \\
\text { ações; interatividade: } \\
\text { estabelecimento de relações. }\end{array}$ & $\mathrm{x}$ & $\mathrm{x}$ & & \\
\hline Moncada e Ospina (2008) & $\begin{array}{l}\text { Trabalho conjunto: } \\
\text { objetivos em comum }\end{array}$ & $\mathrm{x}$ & & & \\
\hline Morais e Cabrita (2008) & $\begin{array}{l}\text { Trabalho conjunto: ações } \\
\text { conjuntas; aprendizagem: } \\
\text { autoaprendizagem; } \\
\text { conhecimento: construção } \\
\text { coletiva. }\end{array}$ & $\mathrm{x}$ & & $\mathrm{x}$ & $\mathrm{x}$ \\
\hline
\end{tabular}




\begin{tabular}{|c|c|c|c|c|c|}
\hline $\begin{array}{l}\text { Morales-Bueno e Gómez- } \\
\text { Nocetti (2009) }\end{array}$ & $\begin{array}{l}\text { Trabalho conjunto: } \\
\text { grupo com habilidades } \\
\text { cognitivas; interatividade: } \\
\text { estabelecimento de } \\
\text { relações; aprendizagem: } \\
\text { aprendizagem mediada. }\end{array}$ & $\mathrm{x}$ & $\mathrm{x}$ & $\mathrm{x}$ & \\
\hline $\begin{array}{l}\text { Padilla-Beltrán, Vega-Rojas } \\
\text { e Rincón-Caballero (2014) }\end{array}$ & $\begin{array}{l}\text { Interatividade: } \\
\text { interatividade virtual; } \\
\text { aprendizagem: } \\
\text { aprendizagem mediada. }\end{array}$ & & $\mathrm{x}$ & $\mathrm{x}$ & \\
\hline Pranke e Frison (2015) & $\begin{array}{l}\text { Trabalho conjunto: objetivos } \\
\text { em comum, negociação } \\
\text { coletiva, liderança } \\
\text { compartilhada, condução } \\
\text { das ações; interatividade: } \\
\text { estabelecimento de relações, } \\
\text { corresponsabilidade. }\end{array}$ & $\mathrm{x}$ & $\mathrm{x}$ & & \\
\hline Rabello (2015) & $\begin{array}{l}\text { Aprendizagem: ensino e } \\
\text { aprendizagem eficaz. }\end{array}$ & & & $\mathrm{x}$ & \\
\hline Salomão (2011) & $\begin{array}{l}\text { Trabalho conjunto: } \\
\text { objetivos em comum. }\end{array}$ & $\mathrm{x}$ & & & \\
\hline Sanches e Lopes (2008) & $\begin{array}{l}\text { Interatividade: interação } \\
\text { virtual; aprendizagem: } \\
\text { troca de aprendizagem; } \\
\text { conhecimento: } \\
\text { compartilhamento de } \\
\text { conhecimento. }\end{array}$ & & $\mathrm{x}$ & $\mathrm{x}$ & $\mathrm{x}$ \\
\hline $\begin{array}{l}\text { Santos Junior e Marcondes } \\
\text { (2013) }\end{array}$ & $\begin{array}{l}\text { Trabalho conjunto: } \\
\text { objetivos em comum, } \\
\text { negociação coletiva, } \\
\text { confiança mútua. }\end{array}$ & $\mathrm{x}$ & & & \\
\hline Silva (2015) & $\begin{array}{l}\text { Aprendizagem: } \\
\text { aprendizagem mediada. }\end{array}$ & & & $\mathrm{x}$ & \\
\hline Torres e Siqueira (2012) & $\begin{array}{l}\text { Interatividade: interação } \\
\text { virtual. }\end{array}$ & & $\mathrm{x}$ & & \\
\hline
\end{tabular}

Fonte: elaborado pelas autoras (2017).

Verifica-se, no Gráfico 1, que, na definição da prática de aprendizagem colaborativa, a expressão "trabalho conjunto" está presente em metade dos artigos analisados (36,1\%); já a menção à interatividade ocorre em apenas 25,0\% dos artigos, assim como o foco no uso dessa proposta para que a aprendizagem ocorra pelo compartilhamento entre os pares. Também em número reduzido $(13,9 \%)$ encontra-se a menção, nas definições, ao uso da proposta como finalidade de construção de conhecimento coletivo. 
Gráfico 1 - Conceito de aprendizagem colaborativa

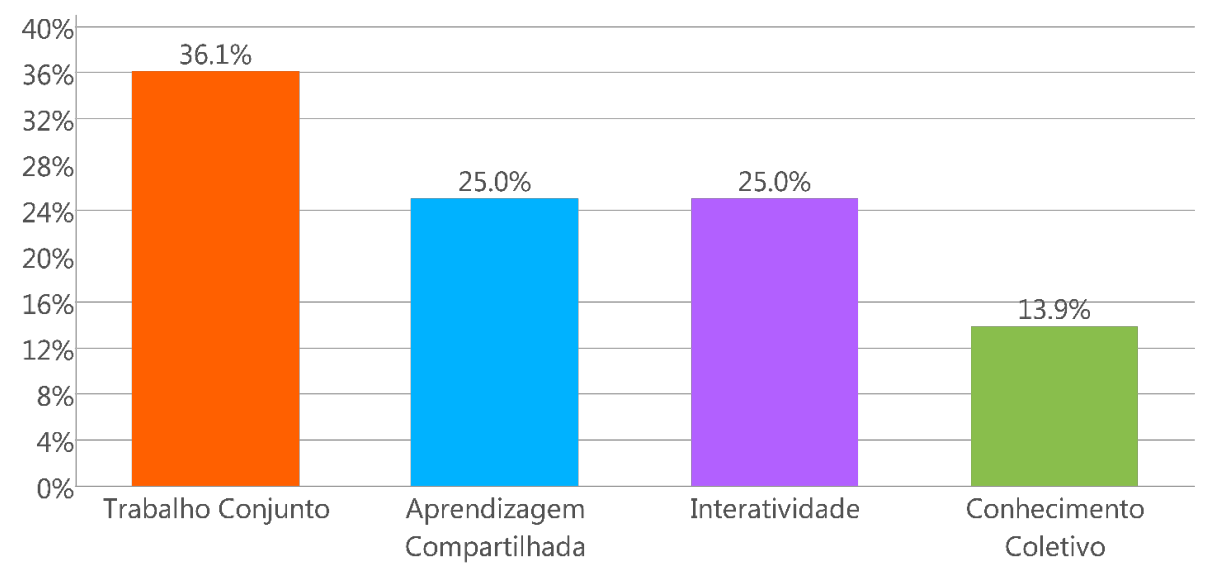

Fonte: elaborado pelas autoras (2017).

Complementarmente, a figura 1 apresenta as características da aprendizagem colaborativa em cada um dos elementos categorizados.

Figura 1 - Conceito de aprendizagem colaborativa

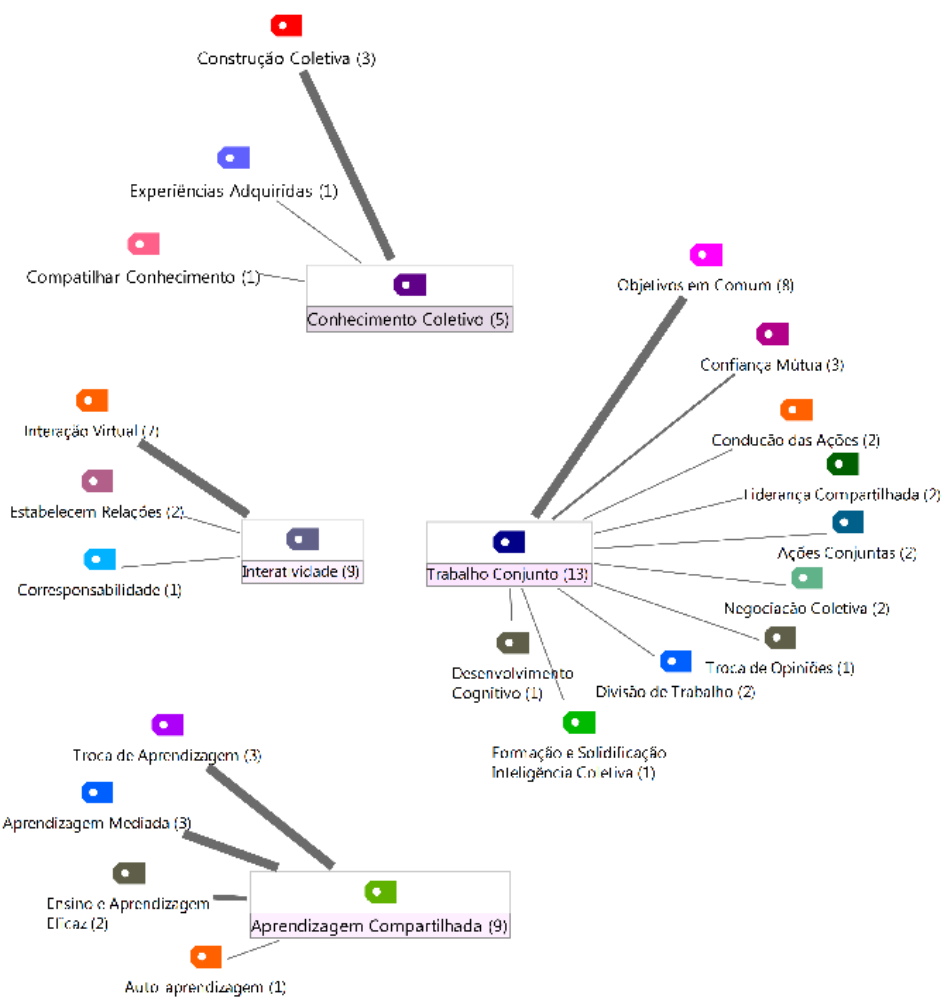

Fonte: imagem gerada pelo software MaxQDA a partir dos dados codificados nos artigos. 
Observa-se que as características do conhecimento coletivo (cinco artigos) são: a construção coletiva (ARAVENA-REYES, 2001, MORAIS; CABRITA, 2008; ECHAVARRIA; HERNÁNDEZ, 2013), o compartilhamento das experiências adquiridas (GIANNOTTI; DINIZ, 2010) e o compartilhamento de outros tipos de conhecimento (SANCHES; LOPES, 2008). Por sua vez, a interatividade (nove artigos) tem por finalidade o estabelecimento de relações entre os aprendizes (MORALES-BUENOA; GÓMEZ-NOCETTI, 2009; MARCHIORI; GREEF, 2014; PRANKE; FRISON, 2015) e a geração de corresponsabilidade (PRANKE; FRISON, 2015), sendo essas ações predominantemente virtuais (ARAVENA-REYES, 2001; SANCHES; LOPES, 2008; GIANNOTTI; DINIZ, 2010; TORRES; SIQUEIRA, 2012; ECHAVARRIA; HERNÁNDEZ, 2013; PADILLA-BELTRÁN; VEJA-ROJAS; RICÓN-CABALLERO, 2014).

Outro aspecto identificado nos artigos diz respeito especificamente à aprendizagem compartilhada (nove artigos), sendo ela distribuída entre trocas para que ocorra a aprendizagem (SANCHES; LOPES, 2008; GIANNOTTI; DINIZ, 2010; FIGUEROA; AILLON, 2015), aprendizagem mediada (MORALES-BUENOA; GÓMEZ-NOCETTI, 2009; ECHAVARRIA; HERNÁNDEZ, 2013; PADILLA-BELTRÁN; VEJA-ROJAS; RICÓN-CABALLERO, 2014; SILVA, 2015), consideração que esse tipo de aprendizagem é eficaz (RABELLO, 2015) e autoaprendizagem (MORAIS; CABRITA, 2008).

Finalmente, o trabalho em conjunto (13 artigos) é o aspecto mais presente nos artigos analisados; contudo, segundo as definições encontradas, somente é considerado aprendizagem colaborativa quando: existem objetivos comuns nas tarefas a ser realizadas (MONCADA; OSPINA, 2008; ABEGG; BASTOS; MÜLLER, 2010; SALOMÃO, 2011; SANTOS JUNIOR; MARCONDES, 2013; GONZÁLEZ-WEIL et al., 2014; MARCHIORI; GREEF, 2014; FIGUEROA; AILLON, 2015; PRANKE; FRISON, 2015); há confiança mútua (SANTOS JUNIOR; MARCONDES, 2013; MARCHIORI; GREEF, 2014); as ações são conduzidas de forma autônoma (MARCHIORI; GREEF, 2014; PRANKE; FRISON, 2015); a liderança é compartilhada (MARCHIORI; GREEF, 2014; PRANKE; FRISON, 2015); as ações são realizadas conjuntamente (MORAIS; CABRITA, 2008; MARCHIORI; GREEF, 2014); há negociação coletiva (SANTOS JUNIOR; MARCONDES, 2013; PRANKE; FRISON, 2015); respeita-se a troca de opiniões (COGO et al., 2010); há divisão do trabalho (BEDRAN; SALOMÃO, 2013); ocorre desenvolvimento cognitivo durante o processo (MORALES-BUENOA; GÓMEZ-NOCETTI, 2009); e visa à formação e solidificação da inteligência coletiva (ECHAVARRIA; HERNÁNDEZ, 2013).

\section{Benefícios da aprendizagem colaborativa}

Trinta e cinco artigos apresentam os benefícios da prática de aprendizagem colaborativa (Quadro 3). Considerando como categorias de análise também os aspectos elencados por Barkley, Majos e Cross (2014): trabalho conjunto (TC), interatividade (I), aprendizagem compartilhada (AC) e construção de conhecimento coletivo $(\mathrm{CC})$, verificou-se que os artigos analisados revelam pelo menos um benefício associado a uma dessas categorias. 
Quadro 3 - Benefícios da aprendizagem colaborativa

\begin{tabular}{|c|c|c|c|c|c|}
\hline \multirow{2}{*}{ Referência } & \multirow{2}{*}{ Benefício } & \multicolumn{4}{|c|}{ Categorias } \\
\hline & & $\mathrm{TC}$ & $I$ & $\overline{\mathrm{AC}}$ & $\overline{\mathrm{CC}}$ \\
\hline $\begin{array}{l}\text { Abegg, Bastos e Müller } \\
(2010)\end{array}$ & $\begin{array}{l}\text { Interatividade: agregação de } \\
\text { valor ao grupo. }\end{array}$ & & $\mathrm{x}$ & & \\
\hline Araújo e Dieb (2010) & $\begin{array}{l}\text { Interatividade: interação } \\
\text { positiva; associado à } \\
\text { tecnologia: interação em } \\
\text { fórum. }\end{array}$ & $\mathrm{x}$ & $\mathrm{x}$ & & \\
\hline $\begin{array}{l}\text { Arregui, Martín e } \\
\text { Gonçalves (2013) }\end{array}$ & $\begin{array}{l}\text { Conhecimento: } \\
\text { desenvolvimento de } \\
\text { competências. }\end{array}$ & & & & $\mathrm{x}$ \\
\hline Bedran e Salomão (2013) & $\begin{array}{l}\text { Aprendizagem: exploração } \\
\text { de culturas. }\end{array}$ & & & $\mathrm{x}$ & \\
\hline Braga, Rossi e Cole (2010) & $\begin{array}{l}\text { Interatividade: } \\
\text { envolvimento do estudante. }\end{array}$ & & $\mathrm{x}$ & & \\
\hline $\begin{array}{l}\text { Bottentuit Junior e } \\
\text { Coutinho (2008) }\end{array}$ & $\begin{array}{l}\text { Interatividade: relações } \\
\text { pessoais. }\end{array}$ & & $\mathrm{x}$ & & \\
\hline Cogo et al. (2010) & $\begin{array}{l}\text { Interatividade: dinâmica de } \\
\text { grupo. }\end{array}$ & & & & \\
\hline Dias (2011) & $\begin{array}{l}\text { Interatividade: } \\
\text { envolvimento ativo/ } \\
\text { efetivo; conhecimento: } \\
\text { desenvolvimento de } \\
\text { pensamento crítico; } \\
\text { aprendizagem: aumento } \\
\text { da autoestima, redução da } \\
\text { ansiedade. }\end{array}$ & & $\mathrm{x}$ & $\mathrm{x}$ & $\mathrm{x}$ \\
\hline $\begin{array}{l}\text { Echavarria e Hernández } \\
\text { (2013) }\end{array}$ & $\begin{array}{l}\text { Interatividade: } \\
\text { envolvimento ativo/efetivo; } \\
\text { associado à tecnologia: } \\
\text { conteúdo digital. }\end{array}$ & $\mathrm{x}$ & $\mathrm{x}$ & & \\
\hline $\begin{array}{l}\text { Fernández; Ruiz e García } \\
\text { (2015) }\end{array}$ & $\begin{array}{l}\text { Interatividade: relações } \\
\text { pessoais; conhecimento: } \\
\text { desenvolvimento de } \\
\text { competências. }\end{array}$ & & $\mathrm{x}$ & & $\mathrm{x}$ \\
\hline Frison (2016) & $\begin{array}{l}\text { Interatividade: } \\
\text { envolvimento do estudante; } \\
\text { aprendizagem: promoção da } \\
\text { aprendizagem. }\end{array}$ & & $x$ & $\bar{x}$ & \\
\hline Giannotti e Diniz (2010) & $\begin{array}{l}\text { Associado à tecnologia: } \\
\text { ferramentas computacionais; } \\
\text { aprendizagem: construção } \\
\text { de saber pedagógico. }\end{array}$ & $x$ & & $x$ & \\
\hline
\end{tabular}




\begin{tabular}{|c|c|c|c|c|c|}
\hline González-Weil et al. (2014) & $\begin{array}{l}\text { Interatividade: práticas } \\
\text { comunicativas, agregação de } \\
\text { valor ao grupo. }\end{array}$ & & $x$ & & \\
\hline $\begin{array}{l}\text { Holanda, Pinheiro e } \\
\text { Pagliuca (2013) }\end{array}$ & $\begin{array}{l}\text { Interatividade: } \\
\text { envolvimento do estudante; } \\
\text { conhecimento: construção. }\end{array}$ & & $x$ & & $\mathrm{x}$ \\
\hline $\begin{array}{l}\text { Magnagnagno, Ramos e } \\
\text { Oliveira (2015) }\end{array}$ & $\begin{array}{l}\text { Associado à tecnologia: } \\
\text { ferramentas computacionais; } \\
\text { conhecimento: criação de } \\
\text { conteúdo. }\end{array}$ & $x$ & & & $\mathrm{x}$ \\
\hline Marchiori e Greef (2014) & $\begin{array}{l}\text { Interatividade: construção } \\
\text { em grupo, envolvimento } \\
\text { ativo/efetivo; associado à } \\
\text { tecnologia: ferramentas } \\
\text { computacionais. } \\
\end{array}$ & $x$ & $x$ & & \\
\hline Moncada e Ospina (2008) & $\begin{array}{l}\text { Conhecimento: } \\
\text { desenvolvimento de } \\
\text { competências. }\end{array}$ & & & & $\mathrm{x}$ \\
\hline Morais e Cabrita (2008) & $\begin{array}{l}\text { Interatividade: } \\
\text { envolvimento ativo/efetivo. }\end{array}$ & & $x$ & & \\
\hline $\begin{array}{l}\text { Morales-Bueno e Gómez- } \\
\text { Nocetti (2009) }\end{array}$ & $\begin{array}{l}\text { Interatividade: relações } \\
\text { pessoais; aprendizagem: } \\
\text { administração de objetivos. }\end{array}$ & & $x$ & $x$ & \\
\hline $\begin{array}{l}\text { Padilla-Beltrán, Vega-Rojas } \\
\text { e Rincón-Caballero (2014) }\end{array}$ & $\begin{array}{l}\text { Interatividade: discussões } \\
\text { simultâneas. }\end{array}$ & & $x$ & & \\
\hline Pranke e Frison (2015) & $\begin{array}{l}\text { Interatividade: } \\
\text { envolvimento ativo/ } \\
\text { efetivo; conhecimento: } \\
\text { desenvolvimento } \\
\text { de competências; } \\
\text { aprendizagem: promoção da } \\
\text { aprendizagem. }\end{array}$ & & $x$ & $x$ & $\mathrm{x}$ \\
\hline Rabello (2015) & $\begin{array}{l}\text { Interatividade: construção } \\
\text { em grupo; associado à } \\
\text { tecnologia: rede social } \\
\text { virtual; aprendizagem: } \\
\text { novos conceitos/conteúdos. }\end{array}$ & $x$ & $x$ & $x$ & \\
\hline Rangel-S et al. (2012) & $\begin{array}{l}\text { Interatividade: } \\
\text { envolvimento do estudante; } \\
\text { associado à tecnologia: } \\
\text { ambiente virtual de } \\
\text { aprendizagem. } \\
\end{array}$ & $x$ & $x$ & & \\
\hline $\begin{array}{l}\text { Reali, Tancredi e Mizukami } \\
\text { (2008) }\end{array}$ & $\begin{array}{l}\text { Associado à tecnologia: } \\
\text { internet. }\end{array}$ & $x$ & & & \\
\hline
\end{tabular}




\begin{tabular}{|c|c|c|c|c|}
\hline Reis e Silva (2005) & $\begin{array}{l}\text { Interatividade: } \\
\text { envolvimento do estudante; } \\
\text { associado à tecnologia: } \\
\text { interação on-line, } \\
\text { ferramentas de comunicação. }\end{array}$ & $x$ & $\mathrm{x}$ & \\
\hline $\begin{array}{l}\text { Ruiz-Moreno, Pittamiglio e } \\
\text { Furusato (2008) }\end{array}$ & $\begin{array}{l}\text { Interatividade: } \\
\text { envolvimento do estudante; } \\
\text { associado à tecnologia: } \\
\text { interação on-line, } \\
\text { ferramentas de comunicação. }\end{array}$ & $x$ & $x$ & \\
\hline Salomão (2015) & $\begin{array}{l}\text { Interatividade: práticas } \\
\text { comunicativas; associado } \\
\text { à tecnologia: ferramentas } \\
\text { computacionais. }\end{array}$ & $x$ & $x$ & \\
\hline Sanches e Lopes (2008) & $\begin{array}{l}\text { Interatividade: } \\
\text { envolvimento ativo/efetivo. }\end{array}$ & & $x$ & \\
\hline $\begin{array}{l}\text { Santos Junior e Marcondes } \\
\text { (2013) }\end{array}$ & $\begin{array}{l}\text { Interatividade: relações } \\
\text { pessoais; aprendizagem: } \\
\text { administração de objetivos. }\end{array}$ & & $x$ & $x$ \\
\hline Schellens et al. (2007) & $\begin{array}{l}\text { Interatividade: } \\
\text { envolvimento ativo/efetivo. }\end{array}$ & & $x$ & \\
\hline Silva (2015) & $\begin{array}{l}\text { Interatividade: construção } \\
\text { de grupos, envolvimento } \\
\text { ativo/efetivo. }\end{array}$ & & $x$ & \\
\hline Silva e Andriola (2012) & $\begin{array}{l}\text { Interatividade: } \\
\text { envolvimento ativo/efetivo; } \\
\text { associado à tecnologia: } \\
\text { internet, software/ } \\
\text { aplicativos, ferramentas de } \\
\text { comunicação, comunidades } \\
\text { virtuais. }\end{array}$ & $x$ & $x$ & \\
\hline $\begin{array}{l}\text { Struchiner, Ramos e Serpa } \\
\text { Junior (2016) }\end{array}$ & $\begin{array}{l}\text { Interatividade: } \\
\text { envolvimento ativo/efetivo; } \\
\text { associado à tecnologia: } \\
\text { ambiente virtual de } \\
\text { aprendizagem. }\end{array}$ & $x$ & & \\
\hline Tinto (2006) & $\begin{array}{l}\text { Interatividade: } \\
\text { envolvimento ativo/efetivo. }\end{array}$ & & $x$ & \\
\hline Torres e Siqueira (2012) & $\begin{array}{l}\text { Associado à tecnologia: } \\
\text { tecnologia da informação e } \\
\text { comunicação. }\end{array}$ & $x$ & $x$ & \\
\hline
\end{tabular}

Fonte: elaborado pelas autoras (2017). 
Observa-se, no Gráfico 2, que, em 48,2\% dos artigos que mencionam interatividade, esta é fortemente associada ao uso de tecnologias $(25,0 \%)$ para o desenvolvimento da aprendizagem. Apenas 12,5\% dos artigos mencionam a construção do conhecimento coletivo. É importante ressaltar que Bustos $(2005)^{1}$, citado por Padilla -Beltrán, Vega-Rojas e Rincón-Caballero (2014), indica que a maioria dos estudos sobre aprendizagem colaborativa focaliza mais as vantagens do uso ou não da tecnologia nessa abordagem e não os aspectos do desenvolvimento da aprendizagem.

Gráfico 2 - Benefícios da aprendizagem colaborativa

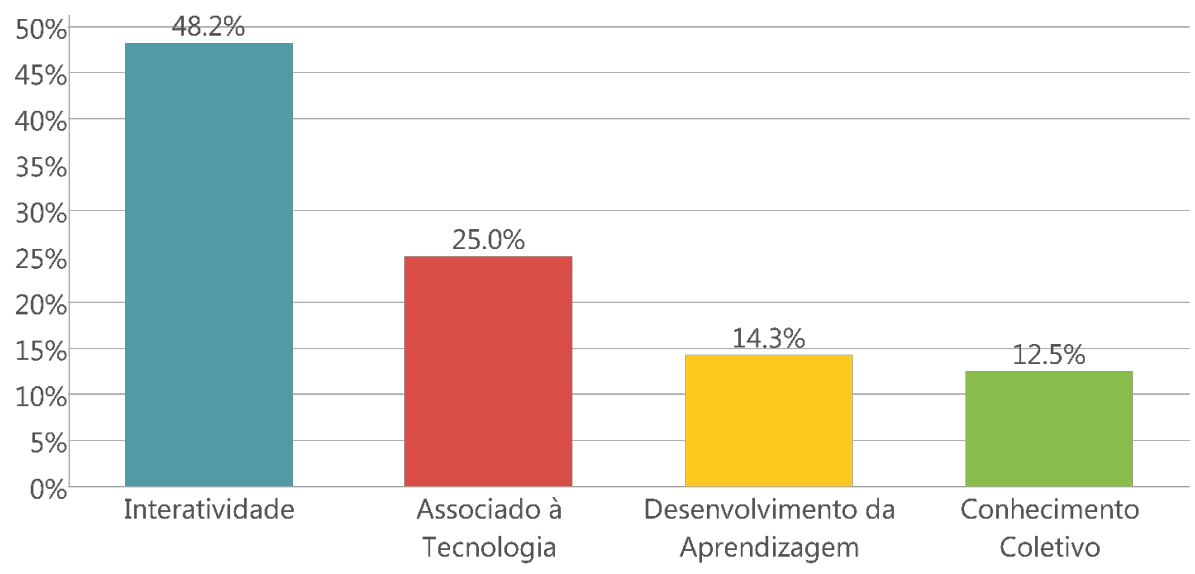

Fonte: elaborado pelas autoras (2017).

Por sua vez, a figura 2 mapa conceitual demonstra as características que compõem os quatro grupos definidos como benefícios da aprendizagem colaborativa. 
Figura 2 - Benefícios da aprendizagem colaborativa
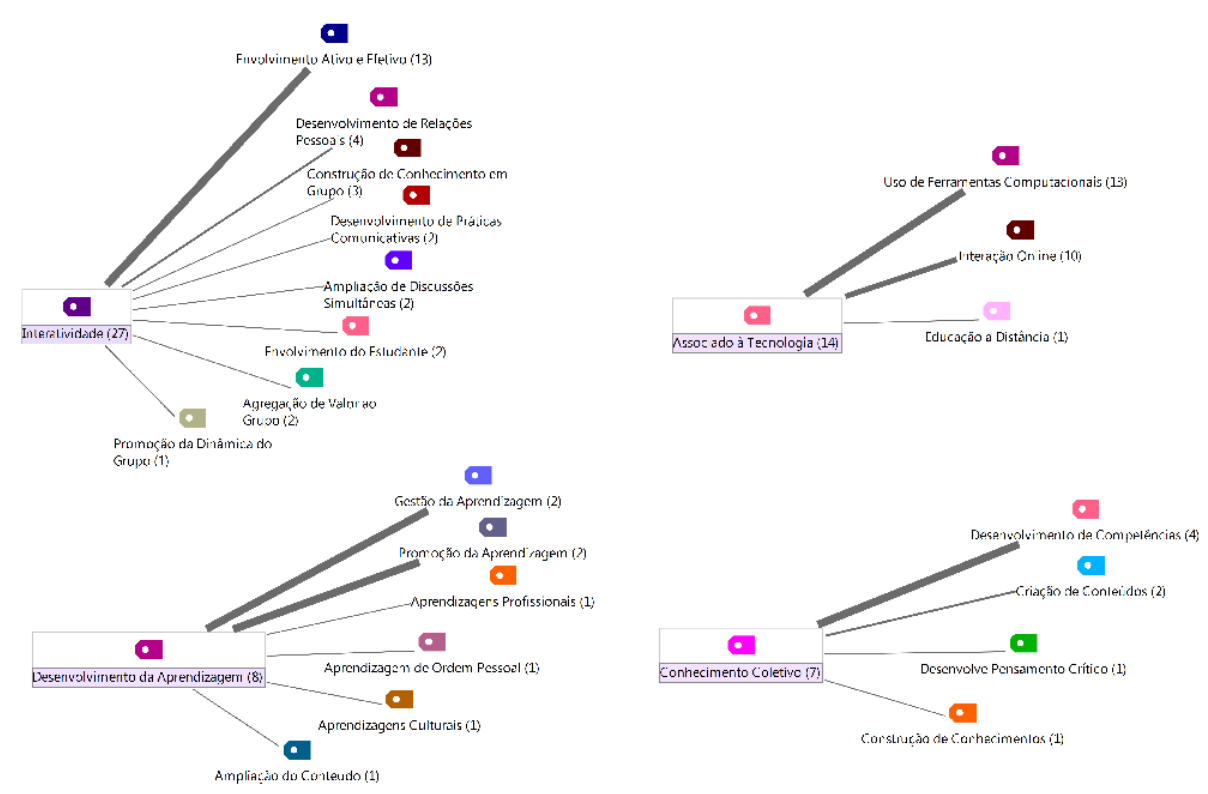

Fonte: imagem gerada pelo software MaxQDA a partir dos dados codificados nos artigos.

Verifica-se que a aprendizagem colaborativa promovendo a interatividade está presente em 28 artigos, tendo sido identificadas nove características. Por sua vez, a interatividade promovendo o envolvimento do estudante de forma ampla aparece em dois artigos (BRAGA; ROSSI; COLE, 2010; FRISON, 2016); o envolvimento ativo/afetivo do estudante é a característica mais recorrente nessa categoria, estando presente em 13 artigos (REIS; SILVA, 2005; TINTO, 2006; SCHELLENS et al., 2007; MORAIS; CABRITA, 2008; SANCHES; LOPES, 2008; DIAS, 2011; RANGEL-S et al., 2012; SILVA; ANDRIOLA, 2012; ECHAVARRIA; HERNÁNDEZ, 2013; HOLANDA; PINHEIRO; PAGLIUCA, 2013; MARCHIORI; GREEF, 2014; PRANKE; FRISON, 2015; STRUCHINER; RAMOS; SERPA JUNIOR, 2016). Outro aspecto da interação citado é o desenvolvimento de relações pessoais, estando presente em quatro artigos (BOTTENTUIT JUNIOR; COUTINHO, 2008; MORALES-BUENOA; GÓMEZ-NOCETTI, 2009; SANTOS JUNIOR; MARCONDES, 2013; FERNÁNDEZ; RUIZ; GARCÍA, 2015).

Com relação ao grupo envolvido no processo de aprendizagem colaborativa, outras possibilidades oferecidas pelo processo de interação são: a agregação de valor ao grupo (ABEGG; BASTOS; MÜLLER, 2010, GONZÁLEZ-WEIL et al., 2014); a possibilidade de construção de conhecimento em grupo (MARCHIORI; GREEF, 2014; RABELLO, 2015; SILVA, 2015); a promoção da dinâmica do grupo (COGO et al., 2010); e também a possibilidade de ampliação das discussões simultâneas (RUIZ-MORENO; PITTAMIGLIO; FURUSATO, 2008; PADILLA-BELTRÁN; VEJA-ROJAS; RICÓN-CABALLERO, 2014). Considerando o desenvolvimento individual do estudante, a interação promove o desenvolvimento de práticas comunicativas (GONZÁLEZ-WEIL et al., 2014; SALOMÃO, 2015). 
A interação é avaliada positivamente no artigo de Araújo e Dieb (2010) quando associada à tecnologia. Essa associação, aliás, está presente em 14 artigos, tendo como características: o uso de ferramentas computacionais (REIS; SILVA, 2005; RUIZ-MORENO; PITTAMIGLIO; FURUSATO, 2008; GIANNOTTI; DINIZ, 2010; TORRES; SIQUEIRA, 2012; ECHAVARRIA; HERNÁNDEZ, 2013; MARCHIORI; GREEF, 2014; RABELLO, 2015; SALOMÃO, 2015), algumas associadas a tecnologias específicas, como uso do fórum (ARAÚJO; DIEB, 2010), outras para criação de conteúdos digitais (MAGNAGNAGNO; RAMOS; OLIVEIRA, 2015), para pesquisa com o uso da internet (REALI; TRANCRED; MIZUKAMI, 2008; SILVA; ANDRIOLA, 2012) e também o uso de aplicativos específicos (SILVA; ANDRIOLA, 2012); a interação on-line (REIS; SILVA, 2005; RUIZ-MORENO; PITTAMIGLIO; FURUSATO, 2008; ARAÚJO; DIEB, 2010; ECHAVARRIA; HERNÁNDEZ, 2013; MARCHIORI; GREEF, 2014; SALOMÃO, 2015) ou comunidades virtuais (SILVA; ANDRIOLA, 2012), por meio da criação de redes sociais (RABELLO, 2015), ou acesso a ambientes virtuais de aprendizagem (RANGELS-S et al., 2012; STRUCHINER; RAMOS; SERPA JUNIOR, 2016). Apenas um artigo faz menção ao uso dessa prática na educação a distância (SILVA; ANDRIOLA, 2012).

$\mathrm{Na}$ categoria "conhecimento coletivo", os sete artigos encontrados trazem como benefícios: o desenvolvimento de competências (MONCADA; OSPINA, 2008; ARREGUI; MARTÍN; GONÇALVES, 2013; FRISON, 2016) e a construção de conhecimentos (HOLANDA; PINHEIRO; PAGLIUCA, 2013; PRANKE, FRISON, 2015; MAGNAGNAGNO; RAMOS; OLIVEIRA, 2015), além da criação de conteúdos (MAGNAGNAGNO; RAMOS; OLIVEIRA, 2015; PRANKE; FRISON, 2015) e do desenvolvimento do pensamento crítico (DIAS, 2011).

Entre os oito artigos classificados na categoria "aprendizagem pelo compartilhamento entre os pares", Pranke e Frison (2015) e Frison (2016) apresentam a aprendizagem colaborativa como benéfica para todos os tipos de aprendizagem, como as aprendizagens culturais (BEDRAN; SALOMÃO, 2013), aprendizagens de ordem pessoal (DIAS, 2011) e aprendizagens profissionais (GIANNOTTI; DINIZ, 2010), além de possibilitar a ampliação de conteúdos apreendidos (RABELLO, 2015) e a aprendizagem da gestão da própria aprendizagem (MORALES-BUENOA; GÓMEZ-NOCETTI, 2009; SANTOS JUNIOR; MARCONDES, 2013).

\section{Desafios no uso da prática de aprendizagem colaborativa}

Também se observou que 40 artigos apresentam desafios relacionados à implementação de uma proposta de aprendizagem colaborativa (Quadro 4). Utilizando como categorias de análise os aspectos: prática $(\mathrm{P})$, tecnologia $(\mathrm{T})$, formação docente (FD), visão do docente (VD) e visão do estudante (VE), identificou-se que 21 artigos correspondem a apenas uma dessas categorias. No entanto, nos demais 19 artigos, as dificuldades entrelaçam-se umas às outras. 
Quadro 4 - Desafios da aprendizagem colaborativa

\begin{tabular}{|c|c|c|c|c|c|c|}
\hline \multirow[t]{2}{*}{ Referência } & \multirow[t]{2}{*}{ Desafio } & \multicolumn{5}{|c|}{ Categorias } \\
\hline & & $\mathbf{P}$ & $\mathrm{T}$ & FD & VD & $\mathrm{VE}$ \\
\hline $\begin{array}{l}\text { Abegg, Bastos e } \\
\text { Müller (2010) }\end{array}$ & $\begin{array}{l}\text { Prática: mudanças e } \\
\text { dificuldades técnicas; } \\
\text { tecnologia: wiki. }\end{array}$ & $\mathrm{x}$ & $\mathrm{x}$ & & & \\
\hline $\begin{array}{l}\text { Arregui, Martín e } \\
\text { Gonçalves (2013) }\end{array}$ & $\begin{array}{l}\text { Prática: contextos flexíveis e } \\
\text { adaptáveis. }\end{array}$ & $\mathrm{x}$ & & & & \\
\hline $\begin{array}{l}\text { Braga, Rossi e Cole } \\
(2010)\end{array}$ & $\begin{array}{l}\text { Visão do docente: } \\
\text { interação do estudante, } \\
\text { enfrentamento de desafios; } \\
\text { visão do estudante: } \\
\text { interação. }\end{array}$ & & & & $\mathrm{x}$ & $\mathrm{x}$ \\
\hline $\begin{array}{l}\text { Bottentuit Junior e } \\
\text { Coutinho }(2008)\end{array}$ & $\begin{array}{l}\text { Prática: tarefas para criação } \\
\text { de grupos; tecnologia: } \\
\text { WebQuest. }\end{array}$ & $\mathrm{x}$ & $\mathrm{x}$ & & & \\
\hline Cogo et al. (2010) & $\begin{array}{l}\text { Prática: conhecimento } \\
\text { do aluno, conhecimento } \\
\text { científico. }\end{array}$ & $\mathrm{x}$ & & & & \\
\hline Cordero (2002) & $\begin{array}{l}\text { Prática: situações externas } \\
\text { ao aluno, experiência do } \\
\text { docente; tecnologia: Taller } \\
\text { de Ensenanza de Física } \\
\text { (TEF). }\end{array}$ & $\mathrm{x}$ & $\mathrm{x}$ & & & \\
\hline Dias (2011) & $\begin{array}{l}\text { Tecnologia: desenho de } \\
\text { mapas; visão do docente: } \\
\text { utilização das ferramentas, } \\
\text { esforço do estudante. }\end{array}$ & & $\mathrm{x}$ & & & $\mathrm{x}$ \\
\hline $\begin{array}{l}\text { Echavarria e } \\
\text { Hernández (2013) }\end{array}$ & $\begin{array}{l}\text { Prática: abordagens } \\
\text { experimentais. }\end{array}$ & $\mathrm{x}$ & & & & \\
\hline Ella et al. (2007) & Visão do docente: conflitos. & $\mathrm{x}$ & & & & \\
\hline $\begin{array}{l}\text { Fernández, Ruiz e } \\
\text { García (2015) }\end{array}$ & $\begin{array}{l}\text { Prática: melhoramento da } \\
\text { investigação, alargamento } \\
\text { da aplicabilidade desse } \\
\text { projeto; tecnologia: } \\
\text { ambiente virtual. }\end{array}$ & $\mathrm{x}$ & $\mathrm{x}$ & & & \\
\hline $\begin{array}{l}\text { Figueroa e Aillon } \\
(2015)\end{array}$ & $\begin{array}{l}\text { Prática: indeterminação do } \\
\text { sistema e design. }\end{array}$ & $\mathrm{x}$ & & & & \\
\hline Frison (2016) & $\begin{array}{l}\text { Prática: experiência; } \\
\text { formação docente: prática. }\end{array}$ & $\mathrm{x}$ & & $\mathrm{x}$ & & \\
\hline $\begin{array}{l}\text { Giannotti e Diniz } \\
(2010)\end{array}$ & $\begin{array}{l}\text { Tecnologia: ambiente } \\
\text { virtual; visão do docente: } \\
\text { inovações tecnológicas. }\end{array}$ & & $\mathrm{x}$ & & $\mathrm{x}$ & \\
\hline
\end{tabular}




\begin{tabular}{|c|c|c|c|c|c|c|}
\hline $\begin{array}{l}\text { González-Weil et } \\
\text { al. (2014) }\end{array}$ & $\begin{array}{l}\text { Formação docente: } \\
\text { incompatibilidade com a } \\
\text { formação. }\end{array}$ & & & $\mathrm{x}$ & & \\
\hline $\begin{array}{l}\text { González, Martín e } \\
\text { Arriba (2016) }\end{array}$ & $\begin{array}{l}\text { Tecnologia: tecnologias da } \\
\text { informação e comunicação; } \\
\text { formação docente; visão do } \\
\text { estudante: atividades em } \\
\text { horário de trabalho. }\end{array}$ & $\mathrm{x}$ & & $\mathrm{x}$ & & $\mathrm{x}$ \\
\hline $\begin{array}{l}\text { Holanda, Pinheiro } \\
\text { e Pagliuca (2013) }\end{array}$ & $\begin{array}{l}\text { Formação docente: } \\
\text { motivação dos estudantes }\end{array}$ & & & $\mathrm{x}$ & & \\
\hline Macêdo (2000) & $\begin{array}{l}\text { Prática: ensino baseado em } \\
\text { conteúdo. }\end{array}$ & $\mathrm{x}$ & & & & \\
\hline $\begin{array}{l}\text { Marchiori e Greef } \\
\text { (2014) }\end{array}$ & $\begin{array}{l}\text { Prática: dificuldades } \\
\text { técnicas. }\end{array}$ & $\mathrm{x}$ & & & & \\
\hline $\begin{array}{l}\text { Moncada e Ospina } \\
(2008)\end{array}$ & $\begin{array}{l}\text { Prática: ensino baseado em } \\
\text { conteúdo. }\end{array}$ & $\mathrm{x}$ & & & & \\
\hline $\begin{array}{l}\text { Morais e Cabrita } \\
(2008)\end{array}$ & $\begin{array}{l}\text { Prática: metodologias } \\
\text { híbridas; tecnologia: acesso } \\
\text { à internet e ao ambiente } \\
\text { virtual; visão do estudante: } \\
\text { utilização da plataforma, } \\
\text { atividades em horário de } \\
\text { trabalho. }\end{array}$ & $\mathrm{x}$ & $\mathrm{x}$ & & & $\mathrm{x}$ \\
\hline $\begin{array}{l}\text { Morales-Bueno e } \\
\text { Gómez-Nocetti } \\
(2009)\end{array}$ & $\begin{array}{l}\text { Prática: complexidade da } \\
\text { tarefa, mediação do docente. }\end{array}$ & $\mathrm{x}$ & & & & \\
\hline $\begin{array}{l}\text { Padilla-Beltrán; } \\
\text { Vega-Rojas e } \\
\text { Rincón-Caballero } \\
\text { (2014) }\end{array}$ & $\begin{array}{l}\text { Prática: atividades, } \\
\text { avaliações, ações. }\end{array}$ & $\mathrm{x}$ & & & & \\
\hline Prado et al. (2012) & $\begin{array}{l}\text { Prática: dificuldades } \\
\text { técnicas, mediação do } \\
\text { docente; tecnologia: } \\
\text { ambiente virtual; } \\
\text { modalidade de ensino: } \\
\text { semipresencial. } \\
\end{array}$ & $\mathrm{x}$ & $\mathrm{x}$ & & & \\
\hline Rabello (2015) & $\begin{array}{l}\text { Tecnologia: sistemas de } \\
\text { redes sociais. }\end{array}$ & & $\mathrm{x}$ & & & \\
\hline $\begin{array}{l}\text { Rangel-S et al } \\
\text { (2012) }\end{array}$ & $\begin{array}{l}\text { Prática: mudanças; } \\
\text { formação docente: carência } \\
\text { de estudos; modalidade de } \\
\text { ensino: educação a distância. }\end{array}$ & $\mathrm{x}$ & & $\mathrm{x}$ & & \\
\hline $\begin{array}{l}\text { Reali; Tancredi e } \\
\text { Mizukami (2008) }\end{array}$ & $\begin{array}{l}\text { Prática: qualidade dos } \\
\text { processos; visão do docente: } \\
\text { sistematização das conversas, } \\
\text { qualidade dos processos. }\end{array}$ & $\mathrm{x}$ & & & $\mathrm{x}$ & \\
\hline
\end{tabular}




\begin{tabular}{|c|c|c|c|c|c|}
\hline Reis e Silva (2005) & Prática: motivação. & $\mathrm{x}$ & & & \\
\hline $\begin{array}{l}\text { Ruiz-Moreno; } \\
\text { Pittamiglio e } \\
\text { Furusato (2008) }\end{array}$ & Tecnologia: ambiente virtual. & & $\mathrm{x}$ & & \\
\hline Salomão (2011) & $\begin{array}{l}\text { Prática: parceria em } \\
\text { trabalhos; formação } \\
\text { docente: parcerias. }\end{array}$ & $\mathrm{x}$ & & $\mathrm{x}$ & \\
\hline Salomão (2015) & $\begin{array}{l}\text { Prática: mediação do } \\
\text { docente; tecnologia: } \\
\text { ambiente virtual. }\end{array}$ & $\mathrm{x}$ & $\mathrm{x}$ & & \\
\hline $\begin{array}{l}\text { Sanches e Lopes } \\
(2008)\end{array}$ & Tecnologias: fórum. & & $\mathrm{x}$ & & \\
\hline $\begin{array}{l}\text { Santos Junior e } \\
\text { Marcondes (2013) }\end{array}$ & $\begin{array}{l}\text { Formação docente: modelo } \\
\text { formativo. }\end{array}$ & & & $\mathrm{x}$ & \\
\hline $\begin{array}{l}\text { Schellens et al. } \\
\text { (2007) }\end{array}$ & Tecnologia: scripts. & & $\mathrm{x}$ & & \\
\hline Silva (2015) & $\begin{array}{l}\text { Prática: articulação do } \\
\text { estudante. }\end{array}$ & $\mathrm{x}$ & & & \\
\hline $\begin{array}{l}\text { Silva e Andriola } \\
(2012)\end{array}$ & $\begin{array}{l}\text { Tecnologia: ambiente } \\
\text { virtual; formação docente: } \\
\text { tecnologia da informação e } \\
\text { comunicação; modalidade } \\
\text { de ensino: educação } \\
\text { a distância, presencial } \\
\text { tradicional. }\end{array}$ & & $\mathrm{x}$ & $\mathrm{x}$ & \\
\hline $\begin{array}{l}\text { Struchiner, Ramos } \\
\text { e Serpa Junior } \\
(2016)\end{array}$ & $\begin{array}{l}\text { Tecnologia: ambiente } \\
\text { virtual; formação docente: } \\
\text { ambiente virtual de } \\
\text { aprendizagem. }\end{array}$ & & $\mathrm{x}$ & $\mathrm{x}$ & \\
\hline Tinto (2006) & $\begin{array}{l}\text { Prática: situações externas } \\
\text { ao aluno. }\end{array}$ & $\mathrm{x}$ & & & \\
\hline $\begin{array}{l}\text { Torres e De La } \\
\text { Torre (2016) }\end{array}$ & $\begin{array}{l}\text { Prática: questionários } \\
\text { confiáveis. }\end{array}$ & $\mathrm{x}$ & & & \\
\hline $\begin{array}{l}\text { Torres e Siqueira } \\
(2012)\end{array}$ & $\begin{array}{l}\text { Prática: planejamento; visão } \\
\text { do docente: planejamento. }\end{array}$ & $\mathrm{x}$ & & & $\mathrm{x}$ \\
\hline
\end{tabular}

Fonte: elaborado pelas autoras (2017).

Observa-se, no Gráfico 3 que a visão que o estudante possa ter desse processo $(8,9 \%)$ não representa um grande desafio. No entanto, a visão do professor $(7,1 \%)$, bem como sua formação $(14,3 \%)$, pode representar um entrave para o desenvolvimento desta prática. Destaca-se que a formação docente, conforme demonstrado no Quadro 4, na maioria das vezes está relacionada à mudança de prática $(46,4 \%)$ ou ao uso das tecnologias $(23,2 \%)$ - e estes aparecem como principais desafios. 
Gráfico 3 - Desafios da prática de aprendizagem colaborativa

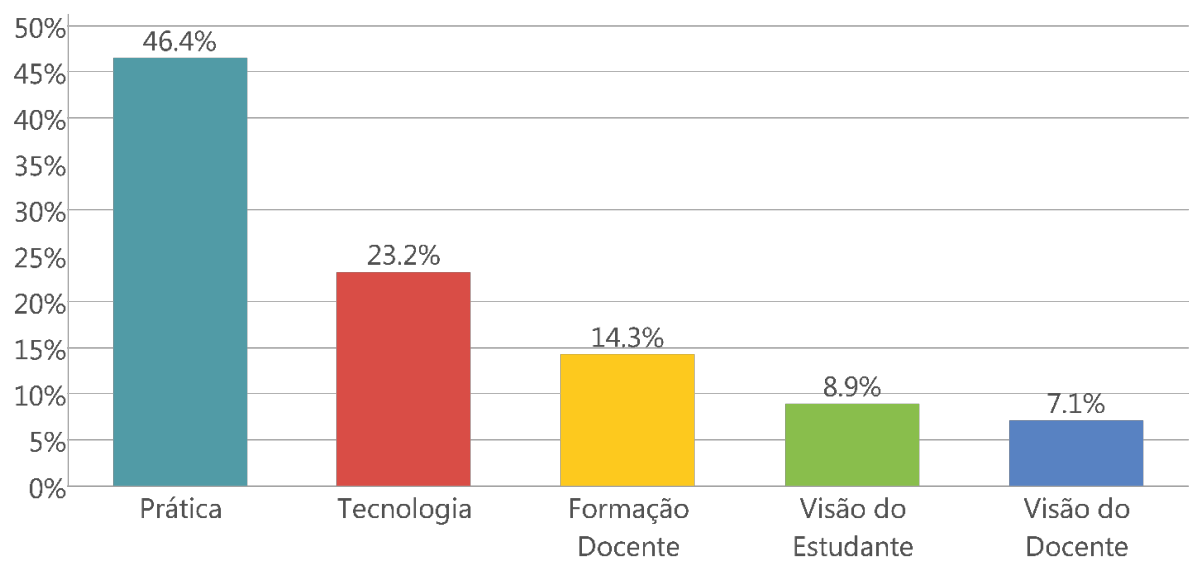

Fonte: elaborado pelas autoras (2017).

Os desafios relacionados à implementação da proposta de aprendizagem colaborativa (Figura 3) são os mais recorrentes (26 artigos) e se referem à elaboração de atividades (13 artigos), à formação do docente para aplicá-las (18 artigos) e à preparação do estudante para realizá-las (oito artigos).

Figura 3 - Desafios relacionados à prática da proposta

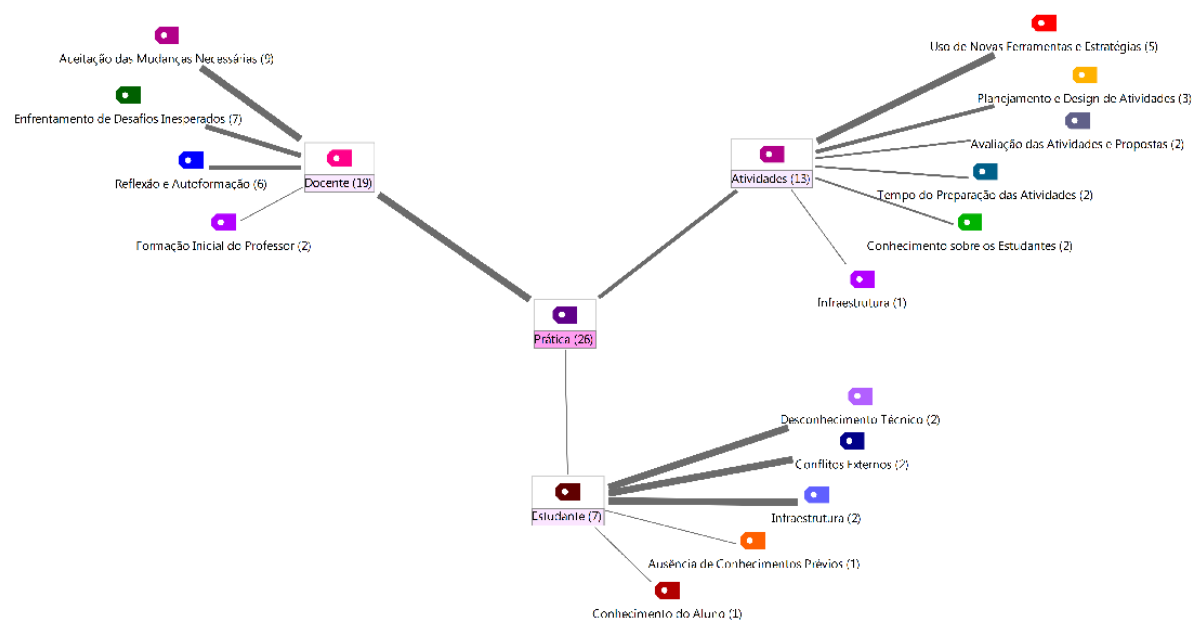

Fonte: imagem gerada pelo software MaxQDA a partir dos dados codificados nos artigos.

No tocante à elaboração de atividades (13 artigos), os desafios referem-se ao uso de novas ferramentas e estratégias necessárias para a implementação da proposta, como as ferramentas wiki (ABEGG; BASTOS; MÜLLER, 2010), WebQuest (BOTTENTUIT JUNIOR; COUTINHO, 2008), estudos de caso (ECHAVAR- 
RIA; HERNÁNDEZ, 2013), metodologias híbridas (MORAIS; CABRITA, 2008), estratégias para mediação (MORALES-BUENO; GÓMEZ-NOCETTI, 2009) e formação dos grupos (BOTTENTUIT JUNIOR; COUTINHO, 2008); à experiência no planejamento e design de atividades que estimulem a colaboração (BOTTENTUIT JUNIOR; COUTINHO, 2008; TORRES; SIQUEIRA, 2012; FIGUEROA; AILLON, 2015); ao conhecimento sobre os estudantes para que as atividades e planejamento aproximem-se de suas realidades (CORDERO, 2002; ARREGUI et al., 2013); ao tempo de preparo dessas atividades (GONZÁLEZ et al., 2016); à avaliação das atividades e propostas implementadas (REALI et al., 2008; TORRES; DE LA TORRE, 2016); e à infraestrutura necessária quando essa prática ocorre virtualmente, como o acesso à internet e aos ambientes virtuais de aprendizagem (MORAIS; CABRITA, 2008).

No que se refere ao docente (19 artigos), observam-se: a importância da aceitação das mudanças necessárias (MACEDO, 2000; MONCADA; OSPINA, 2008; MORAIS; CABRITA, 2008; ABEGG; BASTOS; MÜLLER, 2010; RANGEL-S et al., 2012; ARREGUI; MARTÍN; GONÇALVES, 2013; ECHAVARRIA; HERNÁNDEZ, 2013; PADILLA-BELTRÁN; VEGA-ROJAS; RINCÓN-CABALLERO, 2014; SILVA, 2015); o enfretamento dos desafios inesperados, estando pronto a adaptar e mudar quando necessário, como quando se percebe que os conhecimentos dos estudantes não são suficientes para as atividades planejadas (COGO et al., 2010), quando situações externas interferem no processo de ensino e aprendizagem (CORDERO, 2002; TINTO 2006), quando se percebe que falta motivação nos estudantes para a realização da atividade proposta (HOLANDA; PINHEIRO; PAGLIUCA, 2013), quando ocorrem dificuldades técnicas (MARCHIORI; GREEF, 2014; PRADO et al., 2012) e quando o processo de colaboração não ocorre como esperado (MORALES-BUENO; GÓMEZ-NOCETTI, 2009); a percepção da importância da reflexão e da autoformação de forma contínua (PADILLA-BELTRÁN; VEGA-ROJAS; RINCÓN-CABALLERO, 2014; FERNÁNDEZ; RUIZ; GARCÍA, 2015), pois requer muita preparação e formação (TORRES; SIQUEIRA, 2012; FRISON, 2016), além de reflexão sobre as práticas implementadas para que sejam realizados os ajustes necessários durante o processo (BOTTENTUIT JUNIOR; COUTINHO, 2008; REALI; TANCREDI; MIZUKAMI, 2008); e, no caso de licenciaturas, a utilização e formação para a aprendizagem colaborativa na formação inicial do professor (SALOMÃO, 2011; 2015).

Quanto ao impacto das práticas para o estudante (oito artigos), a ausência de conhecimentos prévios (COGO et al., 2010), o desconhecimento técnico (MARCHIORI; GREEF, 2014; GONZÁLEZ; MARTÍN; ARRIBA, 2016), os desafios impostos pela aprendizagem da gestão do tempo de atividades complexas (TINTO, 2006; GONZÁLEZ; MARTÍN; ARRIBA, 2016), os conflitos externos trazidos para sala de aula, seja virtual, seja presencial (CORDERO, 2002; ELLA et al., 2007), e a falta de infraestrutura (MORAIS; CABRITA, 2008) podem ser desafios a ser suplantados. 
A categoria "tecnologias" (Figura 4) compreende 13 artigos e seus desafios relacionam-se ao uso de ferramentas de colaboração (BOTTENTUIT JUNIOR; COUTINHO, 2008; SANCHES; LOPES, 2008; ABEGG; BASTOS; MÜLLER, 2010; DIAS, 2011; SALOMÃO, 2015); ao manuseio do ambiente virtual (RUIZMORENO; PITTAMIGLIO; FURUSATO, 2008; PRADO et al., 2012; SILVA; ANDRIOLA, 2012; FERNÁNDEZ; RUIZ; GARCÍA, 2015; RABELLO, 2015; STRUCHINER; RAMOS; SERPA JUNIOR, 2016); à infraestrutura (MORAIS; CABRITA, 2008); e a limites tecnológicos do ambiente virtual para a implementação de práticas colaborativas (SCHELLENS et al., 2007).

Figura 4 - Demais desafios da aprendizagem colaborativa
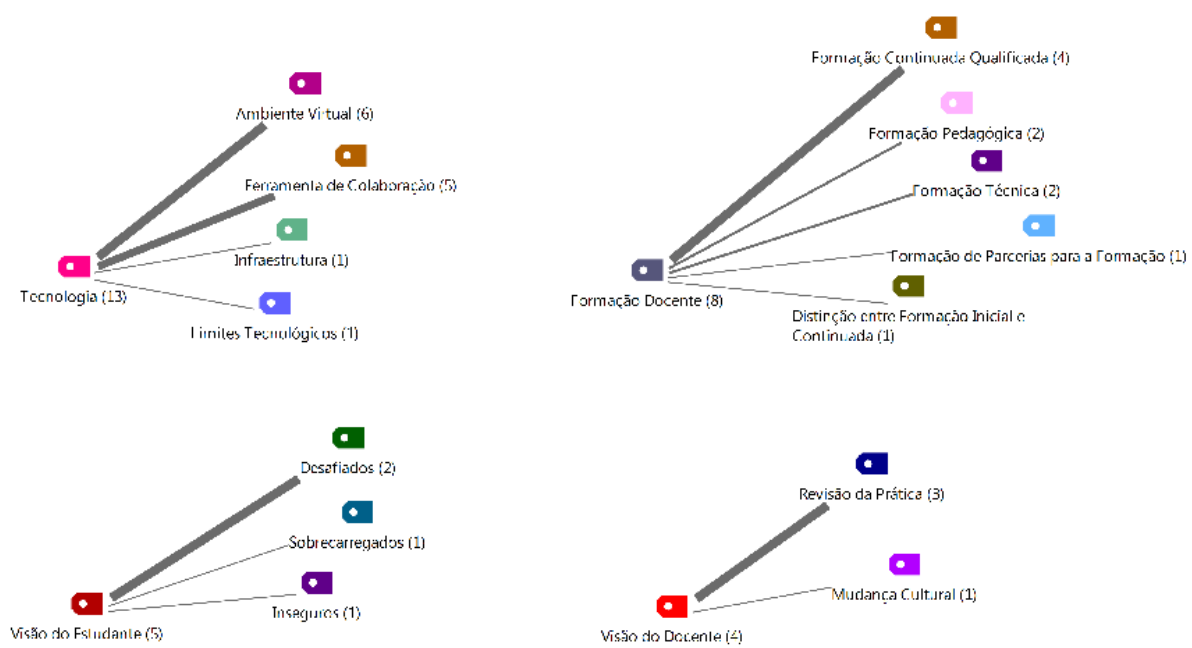

Fonte: imagem gerada pelo software MaxQDA a partir dos dados codificados nos artigos.

Quanto à formação docente (oito artigos), também apresentada no Mapa Conceitual 4, destaca-se a importância de uma formação continuada qualificada para os docentes que decidam utilizar essa prática (RANGELS-S et al., 2012; SANTOS JUNIOR; TORRES; SIQUEIRA, 2012; MARCONDES, 2013; FRISON, 2016), além de ser consideradas propostas tanto para a formação inicial quanto continuada de forma distinta, pois as necessidades são diferentes (GONZÁLEZ-WEIL et al., 2014). Salomão (2011) sugere que, na formação de professores, esta pode ser realizada também mediante parcerias entre estudantes de licenciaturas e professores em exercício. Ainda, os estudos indicam que essa formação deve compreender tanto aspectos pedagógicos (RANGELS-S et al., 2012; SILVA; ANDRIOLA, 2012) quanto técnicos (SILVA; ANDRIOLA, 2012; GONZÁLEZ; MARTÍN; ARRIBA, 2016).

As visões do docente e do estudante (Mapa Conceitual 4) são apresentadas nos artigos como um importante desafio, pois a prática de aprendizagem colaborativa requer um reinvestimento no processo de ensino e aprendizagem. Em relação ao docente, as pesquisas demonstram que ele percebe a necessidade da revisão de sua prática (REALI; TANCREDI; MIZUKAMI, 2008; GIANNOTTI; DINIZ, 2010; 
TORRES; SIQUEIRA, 2012) e de uma mudança cultural (SILVA, 2015). Quanto ao estudante, as pesquisas indicam que há um misto de sentimentos de desafio (BRAGA; ROSSI; COLE, 2010; SILVA, 2015), insegurança (DIAS, 2011) e sobrecarga (DIAS, 2011), devido à mudança de perspectiva de ensino para aprendizagem.

\section{Discussão dos resultados}

$\mathrm{Na}$ discussão dos resultados, enfatiza-se que este estudo de revisão traz um retrato de conceitos predominantes na América Latina, visto que 76\% das revistas nas quais os artigos foram localizados são do Brasil, 20\%, de outros países latino-americanos e apenas dois artigos, de uma revista europeia, porém de língua portuguesa e autores latino-americanos (ARREGUI et al., 2013; GONZÁLEZ; MARTIN; ARRIBA, 2016).

As manifestações encontradas evidenciam quatro principais elementos nas definições sobre aprendizagem colaborativa, sendo eles: trabalho conjunto, interatividade, aprendizagem compartilhada e construção do conhecimento colaborativo, que somam $79,7 \%$ dos resultados.

Trabalho conjunto aparece como o elemento mais empregado nas definições encontradas nos artigos, tendo sido citado por diversos autores e possuindo como características: confiança mútua (JÚNIOR; MARCONDES, 2013), objetivos em comum e liderança compartilhada (PRANKE; FRISON, 2015), condução das ações, ações conjuntas e negociação coletiva (MARCHIORI; GREEF, 2014), troca de opiniões e divisão do trabalho (COGO et al., 2010), formação e solidificação da inteligência dos pares (ECHAVARRIA; HERNÁNDEZ, 2013) e desenvolvimento de habilidades para o trabalho coletivo (ARAVENA, 2001). É importante destacar que, para Barkley, Majos e Cross (2014), o trabalho conjunto, por si só, não é aprendizagem colaborativa. Tem-se, de fato, uma proposta de aprendizagem colaborativa quando há interatividade, aprendizagem compartilhada, construção de conhecimento coletivo e autonomia no processo de aprendizagem, bem como a construção de uma interdependência grupal, com responsabilidade individual.

A perspectiva verificada em várias pesquisas latino-americanas sobre o uso de práticas de aprendizagem colaborativa para o desenvolvimento de habilidades de colaboração (MORALES-BUENOA; GÓMEZ-NOCETTI, 2009; ARREGUI et al., 2013; FERNÁNDEZ et al., 2015; MONCADA; OSPINA, 2008; PRANKE; FRISON, 2015) contraria a distinção necessária entre aprendizagem cooperativa e aprendizagem colaborativa (BRUFFEE, 1995; PANITZ, 1995; ROCKWOOD, 1995; BARKELY; MAJOS; CROSS, 2014), uma vez que as estratégias de aprendizagem cooperativa levariam ao desenvolvimento das habilidades de colaboração, como a interação, liderança, autonomia, entre outras, com uma interdependência grupal, mas com responsabilidade individual; em uma proposta de aprendizagem colaborativa, seriam apenas utilizadas para o desenvolvimento de habilidades cognitivas de alto nível.

A segunda maior incidência foi a interatividade, tendo como principais características a interação virtual (GIANNOTTI; DINIZ, 2010), o estabelecimento de 
relações (MORALES-BUENOA; GÓMEZ-NOCETTI, 2009) e a corresponsabilidade (PRANKE; FRISON, 2015), fundamentais em um ambiente efetivo de aprendizagem, pois aumentam a motivação no processo de aprendizagem (BARKLEY; MAJOS; CROSS, 2014).

Um dos princípios da colaboração é o processo contínuo de interação, que se inicia com a socialização e se dirige para a produção do conhecimento (MINHOTO; MEIRINHOS, 2011). Observa-se aqui que a interação não significa apenas trocas sociais, mas novamente uma interdependência entre os participantes do grupo, assumindo responsabilidades individuais sobre sua aprendizagem, considerando sempre a aprendizagem coletiva (BARKELY; MAJOS; CROSS, 2014). Também é necessário considerar a criação de novos padrões de interação entre as pessoas e as mudanças culturais decorrentes disso, com fortes impactos nos processos de aprendizagem (UNESCO, 2012).

O terceiro aspecto revelado foi a aprendizagem compartilhada, possuindo como características: troca de aprendizagem (GIANNOTTI; DINIZ, 2010), aprendizagem mediada (SILVA, 2015), ensino e aprendizagem eficazes (RABELLO, 2015) e autoaprendizagem (MORAIS; CABRITA, 2008). Nesse contexto, atividades que incitam o compartilhamento de conhecimentos desafiam os estudantes a ser participantes ativos na aquisição e organização do conhecimento, resultando em redes neurais reformatadas e promovendo, assim, uma aprendizagem mais profunda (BARKLEY; MAJOS; CROSS, 2014).

Por fim, como quarto elemento, a construção do conhecimento coletivo é mencionada nas definições, tendo como pressupostos: que seja uma construção coletiva (ARAVENA, 2001), que se respeitem as experiências adquiridas (GIANNOTTI; DINIZ, 2010) e que haja compartilhamento de conhecimento (SANCHES; LOPES, 2008). Por meio da negociação do significado com os outros, os indivíduos podem aprofundar sua própria compreensão, enquanto trabalham no grupo em direção a um entendimento comum (BARKLEY; MAJOS; CROSS, 2014).

Frisa-se que nenhum dos artigos selecionados traz em sua definição de aprendizagem colaborativa a expressão "aprendizagem cooperativa" como sinônimo, parecendo ser esta uma discussão já superada. Assume-se, então, a perspectiva apresentada por Barkley, Majos e Cross (2014), que as distingue pelo nível de autonomia esperado do estudante e pelo nível de regulação do processo de ensino e aprendizagem realizado pelo professor (BRUFFEE, 1995). Nesse sentido, a prática de aprendizagem colaborativa permite que docentes e estudantes construam em conjunto a aprendizagem e compartilhem conhecimentos e experiências.

Os resultados indicam que ela oferece diversos benefícios para o estudante, como o envolvimento ativo nas atividades propostas pelo docente (STRUCHINER; RAMOS; SERPA JUNIOR, 2016), porém a elaboração de atividades que motivem e sejam significativas é um desafio a ser superado (CORDERO, 2002; ARREGUI et al., 2013), visto que isso implica tempo (GONZÁLEZ et al., 2016) e investimento do professor em seu próprio desenvolvimento profissional (PADILLA-BELTRÁN; VEGA-ROJAS; RINCÓN-CABALLERO, 2014). 
Já os benefícios associados às tecnologias representam aspectos importantes para o uso da aprendizagem colaborativa, por estimular e evidenciar a interação dos estudantes, conforme apontam Araújo e Dieb (2010), Giannotti e Diniz (2010), entre outros autores. O conhecimento, por sua vez, é considerado um resultado do uso da prática, mediante interações, cumprimento das atividades definidas para o grupo e contribuições feitas pelos estudantes e seus pares.

Finalmente, constata-se que o resultado da aprendizagem é individual, mas construído de forma compartilhada, podendo os estudantes ter objetivos de aprendizagem diferenciados, pois suas experiências, somadas às dos colegas, permitirão a construção de novas aprendizagens pelo grupo (GIANNOTTI; DINIZ, 2010). Por outro lado, Frison (2016) revela que os docentes não estão preparados para aplicar atividades e estratégias baseadas na aprendizagem colaborativa. Para tanto, desafios de ordem técnica (DIAS, 2011; TORRES; SIQUEIRA, 2012), pedagógica e pessoal (GONZÁLEZ; MARTÍN; ARRIBA, 2016; MORAIS; CABRITA, 2008) precisam ser superados, como a visão que o docente e o estudante têm sobre o processo de ensino e aprendizagem, que os faz privilegiar, muitas vezes, uma proposta de ensino magistral. O investimento na formação pedagógica, para que as estratégias desenvolvidas pelo docente possam ir além do trabalho em grupo, planejando atividades que motivem os estudantes a superar as inseguranças geradas quando da utilização de novas estratégias no processo de ensino e aprendizagem, é outro desafio a ser suplantado.

\section{Conclusões}

Ao discutir os benefícios e desafios da aprendizagem colaborativa no ensino superior, a partir da revisão sistemática de artigos resultantes de pesquisas empíricas, este estudo propôs-se a contribuir para o fortalecimento e promoção do uso dessa prática. Contudo, para que isso se efetive, exigem-se muita preparação e formação do professor para que se tenha sucesso.

Essa preparação pressupõe que, no planejamento das tarefas de aprendizagem e escolha das técnicas de aprendizagem colaborativa a ser utilizadas no processo de ensino e aprendizagem, sejam considerados não apenas os níveis do processo cognitivo que se espera desenvolver, mas também as mudanças esperadas nas atitudes dos estudantes, conforme trabalho desenvolvido por Fink (2013), na taxonomia proposta especificamente para o ensino superior. Igualmente, a formação do professor para preparar os estudantes para o trabalho colaborativo é fundamental, criando estratégias para: quebrar barreiras iniciais que possam prejudicar o desenvolvimento das atividades; encorajar a metacognição; fazer com que se apropriem da proposta da disciplina e como a aprendizagem colaborativa insere-se nela; e auxiliar a criação de regras e procedimentos necessário para o trabalho em grupo.

Ainda, o professor precisa estar preparado para formar e gerir grupos; facilitar o processo de colaboração entre os estudantes; definir métodos para a avaliação do processo e do resultado da aprendizagem realizada de forma colaborativa; e administrar e resolver os problemas que surgem a partir dessa interação intensa entre os estudantes (BARKLEY; MAJOS; CROSS, 2014). Observa-se que os dados encontrados 
nos artigos não apresentam claramente o papel e as implicações no trabalho docente que possam oferecer subsídios para o processo formativo docente.

Diante dos dados apresentados, entende-se que os resultados podem auxiliar os docentes e a universidade quando da opção por práticas que promovam a colaboração entre os estudantes, bem como da avaliação do processo de formação docente referente ao uso da aprendizagem colaborativa e das tecnologias como suporte. Ainda, evidenciam que a adoção dessa prática contribui positivamente para a promoção da aprendizagem dos estudantes e, notoriamente, possibilita a construção do conhecimento de forma compartilhada. Por outro lado, o desconhecimento das potencialidades em relação à sua associação com as tecnologias reforça a carência de formação docente.

As análises realizadas indicam a importância da participação dos estudantes nas estratégias e atividades colaborativas, uma vez que necessitam aprender a buscar a autonomia na própria aprendizagem e construir o conhecimento pela colaboração. $\mathrm{Da}$ mesma forma, sugerem que a prática em estudo é um paradigma na educação superior, ambiente em que o ensino é ainda muito tradicional, e que isso implica a centralidade no estudante. Acentuam, assim, a necessidade de uma revisão das práticas educacionais, considerando a visão da Unesco (2012), que visa a aumentar e fortalecer o uso de práticas inovadoras no ensino superior.

Estudos futuros podem ser direcionados à identificação de atividades e estratégias para a aplicação da aprendizagem colaborativa, além de sua contribuição para a prática docente e o processo de aprendizagem dos estudantes.

\section{Referências}

ABEGG, Ilse; BASTOS, Fábio Purificação; MÜLLER, Felipe Martins. Ensino-aprendizagem colaborativo mediado pelo Wiki do Moodle. Educar em Revista. Curitiba, n. 38, set./dez.2010, p. 205-208. Disponível em: <http://dx.doi.org/10.1590/S0104-40602010000300014>. Acesso em: 13 jun. 2017.

ADAMS BECKER, S., CUMMINS, M., DAVIS, A., FREEMAN, A., HALL GIESINGER, C., AND ANANTHANARAYANAN, V. NMC Horizon Report: 2017 Higher Education Edition. Austin, Texas: The New Media Consortium, 2017. Disponível em: <https://www.nmc. org/publication/nmc-horizon-report-2017-higher-education-edition>. Acesso em: 01 jan. 2018.

ARAÚJO, Júlio César; DIEB, Messias. Interação virtual e a autoria de artigos científicos: nos bastidores da produção acadêmica. Educação em Revista. Belo Horizonte, v. 26 n. 3, dez.2010, p. 387-406. Disponível em: <http://dx.doi.org/10.1590/S0102-46982010000300020>. Acesso em: 13 jun. 2017.

ARAVENA-REYES, José. Metodologias coletivas para o ensino de projeto em engenharia e arquitetura. International Engineering Journal (REM): Revista Escola de Minas. Ouro Preto,v. 54, n.1, jan./mar. 2001. Disponível em: <http://dx.doi.org/10.1590/S0370-44672001000100010〉. Acesso em: 13 jun. 2017.

ARREGUI, Emilio Álvarez; MARTÍN, Alejandro Rodríguez; GONÇALVES, Fernando Ribeiro. Ecosistemas de formación blended learning en la práctica universitaria: valoración de los estudiantes sobre su implementación y efectos en los estilos de aprendizaje. Revista Portuguesa de Educação. Braga, v. 26, n. 1, 2013, p. 143-177. Disponível em: <http://www.scielo.mec.pt/ scielo.php?script=sci_arttext\&pid=S0871-91872013000100007\&lang=pt >. Acesso em: 13 jun. 2017. 
BARKLEY, Elizabth F.; MAJOS, Claire Howell; CROSS, Patricia K. Collaborative learning techniques: a handbook for college faculty. 2. ed. San Francisco/CA: Jossed-Bass. 2014.

BEDRAN, Patricia Fabiana; SALOMÃO, Ana Cristina Biondo. Interação de crenças em contexto colaborativo virtual de aprendizagem de línguas. Revista Brasileira de Linguística Aplicada. Belo Horizonte, v. 13, n. 3, jul./set.2013, p. 789-814. Disponível em: <http://dx.doi. org/10.1590/S1984-63982013005000018>. Acesso em: 13 jun. 2017.

BLASCA, Wanderléia Quinhoneiro et al. Modelo de educação em saúde auditiva. Rev. Espeach, Language, Hearing Science and Education Jounal (CEFAC). São Paulo, v. 16, n. 1, jan./ fev.2014, p. 23-30. Disponível em: <http://dx.doi.org/10.1590/1982-021620141112>. Acesso em: 13 jun. 2017.

BOTTENTUIT JUNIOR, João Batista COUTINHO, Clara Pereira. Análise dos componentes e a usabilidade das WebQuests em língua portuguesa disponíveis na web: um estudo exploratório. Revista de Gestão da Tecnologia e Sistemas de Informação. Journal of Information Systems and Technology Management. Braga, v. 5, n. 3, 2008, p. 453-468. Disponível em: <http://dx.doi.org/10.4301/S1807-17752008000300002>. Acesso em: 13 jun. 2017.

BRAGA, Lucia Willadino; ROSSI, Luciana; COLE, Michaed. Criar uma idiocultura para promover o desenvolvimento de crianças com paralisia cerebral. Educação e Pesquisa. São Paulo, v. 36, n. spe, abr.2010, p. 133-143. Disponível em: <http:/www.scielo.br/scielo.php?script=sci_arttext\&pid=S1517-97022010000400011\&lng=pt\&tlng=pt >. Acesso em: 13 jun. 2017. doi: 10.1590/S1517-97022010000400011.

BRUFFEE, K. A. Sharing Our Toys: Cooperative Learning Versus Collaborative Learning. Change: The Magazine of Higher Learning, v. 27, n. 1, p. 12-18, 1 fev. 1995.

CAMPBELL. Rede Internacional Campbell Collaboration. So you want to write a Campbell systematice review? 2016. Disponível em: <https://www.campbellcollaboration.org/research -resources/writing-a-campbell-systematic-review.html>. Acesso em: 13 jun. 2017.

COGO, Ana Luísa Petersen et al. Aprendizagem de sinais vitais utilizando objetos educacionais digitais: opinião de estudantes de enfermagem. Revista Gaúcha de Enfermagem (on-line). Porto Alegre, v. 31, n. 3, set.2010, p. 435-441. Disponível em: <http://dx.doi.org/10.1590/ S1983-14472010000300005 >. Acesso em: 13 jun. 2017.

CORDERO, Silvina. O taller de ensenanza de física: inovações e pressupostos de uma proposta universitária de aprendizagem colaborativa. Ensaio Pesquisa em Educação em Ciências. Belo Horizonte, v. 4, n. 1, jan./jun.2002, p. 09-27. Disponível em: <http://dx.doi.org/10.1590/1983$21172002040102>$. Acesso em: 13 jun. 2017.

DIAS, Reinildes. Concept maps powered by computer software: a strategy for enhancing reading comprehension in English for Specific Purposes. Revista Brasileira de Linguística Aplicada. Belo Horizonte, v. 11, n. 4,2011, p. 895-911. Disponível em: <http://dx.doi.org/10.1590/ S1984-63982011000400006>. Acesso em: 13 jun. 2017.

ECHAVARRIA, Alfredo Luis Menéndez; HERNÁNDEZ, Claudia Marcela Sánchez. Uso de plataformas social media en la práctica docente universitaria: investigación biográfico-narrativa en un estudio de caso. Signo y Pensamiento. Bogotá, v. 32, n. 63, july/dec.2013, p. 152-168. Disponível em: <http://www.scielo.org.co/scielo.php?script=sci_arttext\&pi$\mathrm{d}=$ S0120-48232013000200009\&lang=pt $>$. Acesso em: 13 jun. 2017.

ELLA, Mebane Minou et al. Gender differences in online collaborative learning groups promoting affective education and social capital. Psicologia Escolar Educacional. Campinas, v. 11, n. spe, dec.2 007, p. 27-33. Disponível em: <http://dx.doi.org/10.1590/S1413$85572007000300003>$. Acesso em: 13 jun. 2017.

FERNÁNDEZ, Nantalia González; RUIZ, Rosa García; GARCÍA, Antonia Ramírez. Aprendizaje cooperativo y tutoría entre iguales en entornos virtuales universitarios. Estudios Pedagógicos. Valdivia, v. 41, n. 1, 2015, p. 111-124. Disponível em: <http://dx.doi.org/10.4067/S071807052015000100007>. Acesso em: 13 jun. 2017. 
FIGUEROA, Beatriz; AILLON, Mariana. Escritura académica de un ensayo mediado por el aprendizaje colaborativo virtual. Estudios Pedagógicos. Valdivia, v. 41, n. 1, 2015, p. 79-91. Disponível em: <http://dx.doi.org/10.4067/S0718-07052015000100005>. Acesso em: 13 jun. 2017.

FINK, L. D. Creating significant learning experiences: an integrated approach to designing college courses, 2nd ed. San Francisco: Jossey-Bass, 2013.

FRISON, Lourdes Maria Bragagnolo. Monitoria: uma modalidade de ensino que potencializa a aprendizagem colaborativa e autoregulada. Pro-Posições. Campinas, v. 27, n. 1, jan./abr.2016, p. 133-153. Disponível em: <http://dx.doi.org/10.1590/0103-7307201607908>. Acesso em: 13 jun. 2017.

GIANNOTTI, Dulcinéia Ester Pagani; DINIZ, Renato Eugênio da Silva. Formação inicial de professores de biologia: a metodologia colaborativa mediada pelo computador e a aprendizagem para a docência. Ciência e Educação. Bauru, v. 16, n. 3, 2010, p. 631-648. Disponível em: <http://dx.doi.org/10.1590/S1516-73132010000300009>. Acesso em: 13 jun. 2017.

GONZÁLEZ-WEIL, Corina et al. Principios de desarrollo profesional docente construidos por y para profesores de ciencia: una propuesta sustentable que emerge desde la indagación de las propias prácticas. Estudios Pedagógicos. Valdivia, v. 40, n. esp. 2014, p. 105-126. Disponível em: <http://dx.doi.org/10.4067/S0718-07052014000200007>. Acesso em: 13 jun. 2017.

GONZÁLEZ, Marcos C.; MARTÍN, Sonia C.; ARRIBA, Jorge M. Experiencias de trabajo colaborativo mediante tecnologías de la información y la comunicación entre profesores. Revista Portuguesa de Educação. Braga, v. 29, n. 1, jun.2016, p. 75-98. Disponível em: <http:// www.scielo.mec.pt/scielo.php?script=sci_arttext\&pid=S0871-91872016000100005\&lang=pt>. Acesso em: 13 jun. 2017. doi: 10.21814/rpe.6996.

HOLANDA, Viviane Rolim; PINHEIRO, Ana Karina Bezerra; PAGLIUCA, Lorita Marlena Freitag. Aprendizagem na educação on-line: análise de conceito. Revista Brasileira de Enfermagem. Brasília, v. 66, n.3, maio/jun. 2013, p. 406-411. Disponível em: <http://dx.doi. org/10.1590/S0034-71672013000300016>. Acesso em: 13 jun. 2017.

JOHNSON, D.; JOHNSON, R. Learning together and alone, cooperative, competitive, and individualistic learning. Needham Heights, MA: Prentice-Hall, 1994.

JOHNSON, D.; JOHNSON, R.; HOLUBEC, E. Advanced Cooperative Learning. Edin, MN: Interaction Book Company, 1988.

LEW, M.; MESCH, D.; JOHNSON, D.W.; JOHNSON, R.T. Positive interdependence, academic and collaborative-skills group, contingencies, and isolated students. American Educational Research Journal, 23 (3), 476-88, 1986.

MACÊDO, Shirley Martins de. Psicologia clínica e aprendizagem significativa: relatando uma pesquisa fenomenológica colaborativa. Psicologia em Estudo. Maringá, v. 5, n. 2, 2000, p. 5176. Disponível em: <http://dx.doi.org/10.1590/S1413-73722000000200005>. Acesso em: 13 jun. 2017.

MAGNAGNAGNO, Cleber Cicero; RAMOS, Monica Parente; OLIVEIRA, Lucila Maria Pesce. Estudo sobre o uso do Moodle em cursos de especialização a distância da Unifesp. Revista Brasileira de Educação Médica. Rio de Janeiro, v. 39, n. 4, out./dez.2015, p. 507-516. Disponível em: <http://dx.doi.org/10.1590/1981-52712015v39n4e00842014>. Acesso em: 13 jun. 2017.

MARCHIORI, Patricia Zeni; GREEF, Ana Carolina. Atividade de escrita colaborativa: percepção de alunos, princípio cooperativo de Grice e social loafing. Educação Pesquisa. São Paulo, v. 40, n. 2, abr./jun.2014, p. 467-482. Disponível em: <http://dx.doi.org/10.1590/S151797022013005000029>. Acesso em: 13 jun. 2017. 
MAXQDA. The art of data analysis. s. d. Disponível em: <http://www.maxqda.com>. Acesso em: 13 jun. 2017.

MINHOTO, Paula; MEIRINHOS, Manuel. As redes sociais na promoção da aprendizagem colaborativa: um estudo no ensino secundário. Educação, Formação \& Tecnologias, v.4, n2, nov. 2011, p. 25-34. Disponível em: <http://eft.educom.pt/index.php/eft/article/view/227>. Acesso em: 13 jun. 2017.

MONCADA, Adriana González; OSPINA, Nelly Sierra. Retos y Posibilidades de la enseñanza del inglés basada en contenidos en la educación superior: visión de los docentes en una experiencia en Colombia. Nucleo, v. 20, n. 25, dez.2008, p. 125-148. Disponível em: <http:// bibliotecadigital.udea.edu.co/bitstream/10495/2971/1/Sierra_Nelly_2008_retos_posibilidades_ense\%C3\%B1anza.pdf >. Acesso em: 13 jun. 2017.

MORAIS, Nídia Salomé; CABRITA, Isabel. B-Learning: impacto no desenvolvimento de competências no ensino superior politécnico. Tékhne - Revista de Estudos Politécnicos. Barcelos. n. 9, jun.2008. Disponível em: <http://www.scielo.mec.pt/scielo.php?script=sci_arttext\&pid=S1645-99112008000100011\&lang=pt>. Acesso em: 26 jun. 2017.

MORALES-BUENOA, Patricia; GÓMEZ-NOCETTI, Viviana. Adaptación de la escala atribucional de motivación de logro de Manassero y Vázquez. Edución y Educadores. Educ. Educ., v. 12, n. 3, sep./dec.2009, p. 33-52. Disponível em: <http://www.scielo.org.co/scielo. php?script=sci_arttext\&pid=S0123-12942009000300003\&lang=pt $>$. Acesso em: 13 jun. 2017.

PADILLA-BELTRÁN, José Eduardo; VEGA-ROJAS, Paula Lizette; RINCÓN-CABALLERO, Diego Armando. Tendencias y dificultades para el uso de las TIC en educación superior. Entramado. Cali, v. 10, n. 1, jan./jun.2014, p. 272-295. Disponível em: <http://www.scielo.org. co/scielo.php?script=sci_arttext\&pid=S1900-38032014000100017\&lang=pt $>$. Acesso em: 13 jun. 2017.

PANITZ, T. Collaborative Versus Cooperative Learning -a Comparison of the Two Concepts Which Will Help Us Understand theUnderlying Nature of Interactive Learning. ERIC Digest, p. 13, 1999.

PRADO, Claúdia et al. Ambiente virtual de aprendizagem no ensino de enfermagem: relato de experiência. Revista Brasileira de Enfermagem. Brasília, v. 65, n. 5, set./out.2012, p. 862-866. Disponível em: <http://dx.doi.org/10.1590/S0034-71672012000500022>. Acesso em: 13 jun. 2017. doi: 10.1590/S0034-71672012000500022.

PRANKE, Amanda; FRISON, Lourdes Maria Bragagnolo. Potencialização da Aprendizagem autorregulada de bolsistas do PIBID/UFPel do curso de licenciatura em matemática através de oficinas pedagógicas. Bolema: Boletim de Educação Matemática. Rio Claro, v. 29, n. 51, abr.2015, p. 223-240. Disponível em: <http://dx.doi.org/10.1590/1980-4415v29n51a12>. Acesso em: 13 jun. 2017. doi: 10.1590/1980-4415v29n51a12.

RABELLO, Cíntia Regina Lacerda. Interação e aprendizagem em sites de redes sociais: uma análise a partir das concepções sócio-históricas de Vygotsky e Bakhtin. Revista Brasileira de Linguística Aplicada. Belo Horizonte, v. 15, n. 3, jul./set.2015, p. 735-760. Disponível em: <http://dx.doi.org/10.1590/1984-639820156288>. Acesso em: 13 jun. 2017.

RANGEL-S, Maria Ligia et al. Redes de aprendizagem colaborativa: contribuição da educação a distância no processo de qualificação de gestores do Sistema Único de Saúde - SUS. Interface - Comunicação, Saúde, Educação. Botucatu, v. 16, n. 41, abr./jun.2012, p. 545-555. Disponível em: <http://dx.doi.org/10.1590/S1414-32832012005000031>. Acesso em: 13 jun. 2017.

REALI, Aline Maria de Medeiros Rodrigues; TANCREDI, Regina Maria Simões Puccinelli; MIZUKAMI, Maria da Graça Nicoletti. Programa de mentoria on-line: espaço para o desenvolvimento profissional de professoras iniciantes e experientes. Educação e Pesquisa. São Paulo, v. 34, n. 1, jan./abr. 2008, p. 077-095. Disponível em: <http://dx.doi.org/10.1590/S151797022008000100006>. Acesso em: 13 jun. 2017. 
REIS, Susana Cristina dos; SILVA, Valdir. Diferenças e semelhanças entre padrões de interação on-line em cursos de duas áreas distintas: bioquímica da nutrição e língua inglesa. Revista Brasileira de Linguística Aplicada. Belo Horizonte, v. 5, n. 1, 2005, p. 2013-236. Disponível em: <http://dx.doi.org/10.1590/S1984-63982005000100011>. Acesso em: 26 jun. 2017.

ROCKWOOD, H. S. III. "Cooperative and collaborative learning" The national teaching \& learning forum, 4 (6), 8-9, 1995.

RUIZ-MORENO, Lidia; PITTAMIGLIO, Silvia Elsa Lizarraldi; FURUSATO, Meiry Akiko. Lista de discussão como estratégia de ensino-aprendizagem na pós-graduação em saúde. Interface - Comunicação, Saúde, Educação. Botucatu, v. 12, n. 27, out./dez.2008, p. 883-892. Disponível em: <http://dx.doi.org/10.1590/S1414-32832008000400017>. Acesso em: 26 jun. 2017.

SALOMÃO, Ana Cristina Biondo. A formação do formador de professores: perspectivas de colaboração entre graduandos e pós-graduandos no projeto Teletandem Brasil. Revista Brasileira de Linguística Aplicada. Belo Horizonte, v. 11, n. 3, 2011, p. 653-677. Disponível em: <http://dx.doi.org/10.1590/S1984-63982011000300004>. Acesso em: 26 jun. 2017.

SALOMÃO, Ana Cristina Biondo. Teletandem and telepresence: rethinking the cultural component in language teaching and language teacher education. Documentação de Estudos em Linguística Teórica e Aplicada (DELTA). São Paulo, v. 31, n. 3, dec.2015, p. 781-800. Disponível em: <http://dx.doi.org/10.1590/0102-4450988061656980825> Acesso em: 26 jun. 2017.

SANCHES, Luiz Miguel Picelli; LOPES, Maria Helena Baena de Morais. Educação a distância sobre cardioversão e desfibrilação para enfermeiros. Revista Brasileira de Enfermagem. Brasília, v. 61, n. 5, set./out.2008, p. 583-588. Disponível em: < http://dx.doi.org/10.1590/ S0034-71672008000500009>. Acesso em: 26 jun. 2017.

SANTOS JUNIOR, João Batista Santos; MARCONDES, Maria Eunice Ribeiro. Grupos colaborativos como ferramenta na reestruturação do modelo didático do professor de química. Ciência e Educação. Bauru, v. 19, n. 3, 2013, p. 695-713. Disponível em: <http://dx.doi. org/10.1590/S1516-73132013000300012>. Acesso em: 13 jun. 2017.

SCHELLENS, Tammy et al. The effects of two computer-supported collaborative learning (CSCL) scripts on university students' critical thinking. Psicologia Escolar e Educacional. Campinas, v. 11, n. spe, dec.2007, p. 83-92. Disponível em: <http://dx.doi.org/10.1590/S1413$85572007000300008>$. Acesso em: 26 jun. 2017.

SCHIAVON, Sandra Helena. Aplicação da revisão sistemática nas pesquisas sobre formação de professores: uma discussão metodológica. 2015. 64f. Dissertação (Mestrado em Educação) - Pontifícia Universidade Católica do Paraná/PUCPR, Curitiba, 2015.

SCIELO. Scientific Electronic Library Online. Disponível em: <scielo.org>. Acesso em: 13 jun. 2017.

SCIELO. Scientific Electronic Library Online. s. d. Disponível em: <http://www.scielo.br/ scielo.php? script=sci_home\&lng=pt\&nrm=iso >. Acesso em: 13 jun. 2017.

SILVA, Andréa Soares Rocha da; ANDRIOLA, Wagner Bandeira. Uso de equações estruturais para validar um modelo explicativo da relação entre domínio tecnológico, interação e aprendizagem colaborativa na educação a distância (EaD). Ensaio: Avaliação e Políticas Públicas em Educação. Rio de Janeiro, v. 20, n. 75, abr./jun.2012, p. 373-396. Disponível em: <http://dx.doi. org/10.1590/S0104-40362012000200008>. Acesso em: 26 jun. 2017.

SILVA, Valdir. Diversidade, redundância e competência distribuída em um sistema virtual de aprendizagem colaborativa. Revista Brasileira de Linguística Aplicada. Belo Horizonte,v. 15, n. 3, jul./set.2015, p. 761-778. Disponível em: <http://dx.doi.org/10.1590/1984-639820156430>. Acesso em: 26 jun. 2017. 
STRUCHINER. Miriam; RAMOS, Paula; SERPA JUNIOR, Octavio Domont de. Desenvolvimento e implementação de um ambiente virtual de aprendizagem na área da saúde: uma experiência de pesquisa baseada em design. Interface - Comunicação, Saúde, Educação. Botucatu, v. 20, n. 57, jun. 2016, p. 485-495. Disponível em: <http://dx.doi.org/10.1590/180757622015.0676>. Acesso em: 26 jun. 2017.

THOMAS, Gary; PRING, Richard. Educação baseada em evidências: a utilização dos achados científicos para a qualificação da prática pedagógica. 1 ed. Porto Alegre: Artmed, 2007.

TINTO, Vincent. Enhancing student persistence: lessons learned in the United States. Análise Psicológica. Lisboa, v. 24, n. 1, jan.2006, p. 7-13. Disponível em: http://www.scielo.mec.pt/scielo.php?script=sci_arttext\&pid=S0870-82312006000100002\&lang=pt. Acesso em: 26 jun. 2017.

TORRES, Aldrin Antonio Carvajal; DE LA TORRE, Nohemy F. Aprendizaje en metodología de investigación para la construcción de la escala diferencial semántico apoyado con mediaciones tecnológicas. Revista Escolar de Administração de Negócios. Bogotá, n. 80, jan./ jun.2016, p. 117-129. Disponível em: <http://www.scielo.org.co/scielo.php?script=sci_arttext\&pid=S0120-81602016000100009\&lang=pt>. Acesso em: 26 jun. 2017.

TORRES, Patricia Lupin; IRALA, Esrom Adriano F. Aprendizagem colaborativa: teoria e prática. Coleção Agrinho. Paraná, 2014, p.1-34. Disponível em: <http:/www.agrinho.com.br/ site/wp-content/uploads/2014/09/2_03_Aprendizagem-colaborativa.pdf >. Acesso em: 26 jun. 2017.

TORRES, Patricia Lupin; SIQUEIRA, Lilia María Marques. Educação virtual nas universidades: as contribuições da aprendizagem colaborativa. Revista Historia de la Edución Latinoamericana. Tunja, v. 14, n. 19, july/dec.2012, p. 175-204. Disponível em: <http://www.scielo.org. co/scielo.php?script=sci_arttext\&pid=S0122-72382012000200009\&lang=pt $>$. Acesso em: 26 jun. 2017. doi: 10.9757/Rhela.19.08.

UNESCO. Glossário de terminologia curricular. Paris, França, 2016, p. 114. Disponível em: <http://unesdoc.unesco.org/images/0022/002230/223059 por.pdf>. Acesso em: 13 jun. 2017.

UNESCO. Organização das Nações Unidas para a Educação, a Ciência e a Cultura. Desafios e perspectivas da educação superior brasileira para a próxima década, 2011-2020. Brasília, 2012, p. 164. Disponível em: <http://unesdoc.unesco.org/images/0021/002189/218964POR.pdf>. Acesso em: 13 jun. 2017.

URZETTA, Fabiana Cardoso; CUNHA, Ana Maria de Oliveira. Análise de uma proposta colaborativa de formação continuada de professores de ciências na perspectiva do desenvolvimento profissional docente. Ciência e Educação. Bauru, v. 19, n. 4, 2013, p. 841-858. Disponível em: <http://dx.doi.org/10.1590/S1516-73132013000400005>. Acesso em: 26 jun. 2017

\section{Notas}

${ }^{1}$ BUSTOS GONZÁLEZ, Atilio. Estrategias didácticas para el uso de TIC`s en la docencia universitaria presencial. Barcelona: Pontificia Universidad Católica de Valparaíso, 2005. 187p.

* Mestranda em Educação pela Pontifícia Universidade Católica do Paraná, Curitiba, Paraná, Brasil.

** Professora doutora da Pontifícia Universidade Católica do Paraná, Curitiba, Paraná, Brasil. 
Possibilidades e desafios da prática de aprendizagem colaborativa no ensino superior

\section{Correspondência}

Dilmeire Sant'Anna Ramos Vosgerau - Pontifícia Universidade Católica do Paraná, Programa de PósGraduação em Educação Stricto Sensu. Rua Imaculada Conceição, 1155, Prado Velho. CEP: 80215-901. Curitiba, Paraná, Brasil.

E-mail: ednalampert@gmail.com - dilmeire.vosgerau@pucpr.br

Recebido em 28 de setembro de 2017

Aprovado em 30 de janeiro de 2018

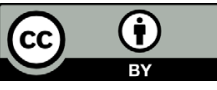

This work is licensed under a Creative Commons Attribution 4.0 International (CC BY 4.0). 
